\title{
Flight and Ground Operations in Support of Airframe Noise Reduction Tests
}

\author{
Ethan Baumann ${ }^{1}$ and Erin R. Waggoner ${ }^{2}$ \\ NASA Armstrong Flight Research Center, Edwards, California, 93523, USA
}

\begin{abstract}
The National Aeronautics and Space Administration (NASA) Acoustic Research Measurements (ARM) project was established to evaluate via flight tests the noise reduction benefits of the Adaptive Compliant Trailing Edge (ACTE) technology along with various main landing gear noise reduction concepts. The ACTE replaces the original Fowler flaps on the NASA SubsoniC Research Aircraft Testbed (SCRAT), thus creating a seamless trailing edge that provides significant noise abatement benefits. The various main landing gear noise reduction concepts are grouped under the LAnding Gear noisE Reduction (LAGER) task and consist of fairings placed on the main landing gear along with two separate treatments applied to the main landing gear wheel well cavities. This paper discusses the tasks necessary to prepare each of these technologies for the ARM flights. The LAGER hardware was taken from model-scale concepts tested in wind tunnels to flight hardware, which had to be cleared as airworthy for the ARM flights. The ACTE flaps were initially intended to be removed from the SCRAT prior to the start of the ARM project. Retaining the ACTE flaps on the aircraft for a longer period of time to support the ARM flights resulted in additional inspections and considerations since the ACTE flaps were flown longer and at certain flight conditions for longer periods of time than initially analyzed. The flight and ground operations required for the ARM tests required extensive coordination among multiple groups and organizations in order to be successful. This paper provides an overview of the hardware development, ground operations, and flight operations which went into acquiring the desired acoustic measurements. In general, the flights were successful and demonstrated the noise reduction benefits of the ACTE flaps, the LAGER gear fairings, and the LAGER gear cavity treatments.
\end{abstract}

\section{Nomenclature}

$3 \mathrm{D}$

ACTE

AFRC

AFRL

ARM

CDR

CFD

CFR

EAFB

ERA

FF

FAA

FAR

FDC

FTE

$\mathrm{g}$

GIII
$=$ three dimensional

$=$ Adaptive Compliant Trailing Edge

= Armstrong Flight Research Center, Edwards, California

= Air Force Research Laboratory, Wright-Patterson Air Force Base, Ohio

$=$ Acoustic Research Measurements

= Critical Design Review

$=$ computational fluid dynamics

$=$ Code of Federal Regulations

= Edwards Air Force Base, Edwards, California

$=$ Environmentally Responsible Aviation

$=$ Fowler flaps

$=$ Federal Aviation Administration

$=$ Federal Aviation Regulation

$=$ flight demonstrations and capabilities

$=$ flight-test engineer

$=$ acceleration of gravity

= Gulfstream III (Gulfstream Aerospace Corporation, Savannah, Georgia)

\footnotetext{
${ }^{1}$ X-57 Deputy Chief Engineer, Systems Engineering \& Integration Branch, P.O. Box 273/MS 4840D, AIAA nonmember.

${ }^{2}$ Aerospace Engineer, Aerodynamics \& Propulsion Branch, P.O. Box 273/MS 4840D, AIAA non-member.
} 


$\begin{array}{ll}\text { GPS } & =\text { global positioning system } \\ \text { GSE } & =\text { ground support equipment } \\ \text { KCAS } & =\text { knots calibrated airspeed } \\ \text { KIAS } & =\text { knots indicated airspeed } \\ \text { Kn } & =\text { knots } \\ \text { LAGER } & =\text { LAnding Gear noisE Reduction } \\ \text { LaRC } & =\text { Langley Research Center, Hampton, Virginia } \\ \text { MLG } & =\text { main landing gear } \\ \text { MSL } & =\text { mean sea level } \\ \text { NASA } & =\text { National Aeronautics and Space Administration } \\ \text { PI } & =\text { principle investigator } \\ \text { SCRAT } & =\text { SubsoniC Research Aircraft Testbed } \\ \text { SODAR } & =\text { sonic detection and ranging } \\ \text { STEAAM } & =\text { Seamless Trailing Edge ACTE Acoustics Measurements } \\ \text { SUAS } & =\text { small unmanned aircraft system } \\ \text { TS } & =\text { transition section } \\ \text { V\&V } & =\text { verification and validation }\end{array}$

\section{Introduction}

Aircraft noise associated with civil aviation operations constitutes an environmental issue that negatively impacts communities near airports during aircraft take-off and landing. Advances in turbofan noise reduction over the past few decades have resulted in the prominence of the airframe as a major component of aircraft noise during approach and landing. Major sources of airframe noise are high-lift devices and the landing gear [1]. Further reduction of aircraft noise cannot be achieved without mitigation of the noise produced by these elements. The National Aeronautics and Space Administration (NASA) Acoustic Research Measurements (ARM) project was established by the NASA Flight Demonstrations and Capabilities (FDC) project to evaluate the noise reduction benefits of the Adaptive Compliant Trailing Edge (ACTE) technology along with various main landing gear (MLG) noise reduction concepts. The ACTE replaced the Fowler flaps on the NASA SubsoniC Research Aircraft Testbed (SCRAT) and created a seamless trailing edge, which previous studies had shown to have the potential to yield significant noise reduction benefits [2]. The ACTE noise reduction efforts are grouped under the Seamless Trailing Edge ACTE Acoustics Measurements (STEAAM) effort. The various main landing gear noise reduction concepts are grouped under the LAnding Gear noisE Reduction (LAGER) effort and consist of fairings placed on the main landing gear along with two separate treatments applied to the MLG wheel well cavities.

In order to accomplish the goals of the ARM project, two separate GIII aircraft (Gulfstream Aerospace Corporation, Savannah, Georgia) were flown over a phased microphone array system developed and operated by personnel from NASA Langley Research Center (LaRC) (Hampton, Virginia). The array was set up on runway 18L on the Rogers Dry Lakebed at Edwards Air Force Base (EAFB) located in the California Mojave Desert for two of the flight campaigns and on the inactive runway 24 located at the North Base of EAFB for a third flight campaign. The microphone array was used to localize prominent sources on the aircraft and measure the noise reduction benefits of each of the technologies being tested.

A significant amount of work went into preparing each of these technologies for flight. The LAGER hardware was taken from a concept tested in wind tunnels [3] to flight hardware that had to be cleared as airworthy for the ARM flights. The ACTE flaps had previously been cleared for flight as part of the NASA Environmentally Responsible Aviation (ERA) project [4-6]. Retaining the ACTE flaps on the aircraft for a longer period of time than originally planned in order to support the ARM flights resulted in additional inspections and considerations since the ACTE flaps were flown longer and at certain flight conditions for longer periods of time than initially analyzed. The flight and ground operations required for the ARM flights necessitated a high level of coordination between multiple organizations in order to be successful. This paper provides an overview of the hardware development, ground operations, and flight operations which were required in order to acquire the ARM flight research data.

\section{Acoustic Research Measurements Overview}

The overarching objective of the ARM flight experiment was to demonstrate via flight tests various concepts to reduce airframe noise. The specific goals were to evaluate the noise reduction potential of the ACTE flap and several landing gear technologies on a component-level (separate) as well as system-level (combined) basis. 
The ARM project consisted of four main areas: the design and development effort to produce the full-scale, flight worthy landing gear fairing and cavity treatment concepts; field operations related to the phased microphone array which included measurements of local meteorological conditions; flight operations conducted with two GIII aircraft; and analysis of the acquired data, which is outside of the scope of this paper.

The ARM flight campaign consisted of three series of flights referred to as ARM I, ARM II, and ARM III. The flight campaigns are summarized in the following paragraphs:

The ARM I flights occurred between August 24, 2016 and October 5, 2016. These flights allowed for a quantification of the in-situ microphone array performance, gathered acoustic baseline data for two GIII aircraft (the SCRAT and the NASA 808 airplane), and allowed for a preliminary assessment of the acoustic benefits of the ACTE flaps. A total of 16 flights were conducted consisting of 3 flights where the pilots practiced their flight techniques and 13 flights where acoustic data were gathered with the array.

The ARM II flights were conducted between August 10, 2017 and October 12, 2017. These flights allowed for a quantification of the acoustic benefits of LAGER MLG fairings, chevron cavity treatment, and mesh cavity treatment in conjunction with the ACTE technology. A total of 17 flights were conducted with both the SCRAT and the NASA 808 airplane. Two of the flights were envelope clearance flights in order to clear the LAGER hardware for flight on the SCRAT. The microphone array collected acoustic data on 16 of the 17 flights. The LAGER hardware was only flown on the SCRAT during the ARM II flights.

The ARM III flights were conducted between March 20, 2018 and May 3, 2018. These flights were conducted with the NASA 808 airplane and with the SCRAT after the removal of the ACTE flaps. The ARM III flights allowed for a direct assessment of the acoustic benefits of the ACTE flap and also allowed for further data to be collected with the LAGER hardware in conjunction with the standard Fowler flap configuration. A total of TBD flights were conducted with the NASA 808 airplane and the SCRAT as part of ARM III.

\section{Acoustic Research Measurements Microphone Array}

The ARM acoustic measurements were acquired with a 250 -ft diameter microphone array specifically developed to acquire airframe noise $[7,8]$. The array consisted of 185 microphones on ground plates along with the associated data acquisition hardware. Acquisition control and signal processing, including array beamforming, was performed with the AVEC, Inc. (Blacksburg, Virginia) Time Domain Beamforming Code [9]. An aerial view of the array is shown in Fig. 1. The array also included several ground speakers, which were used to provide reference tones to calibrate the array.

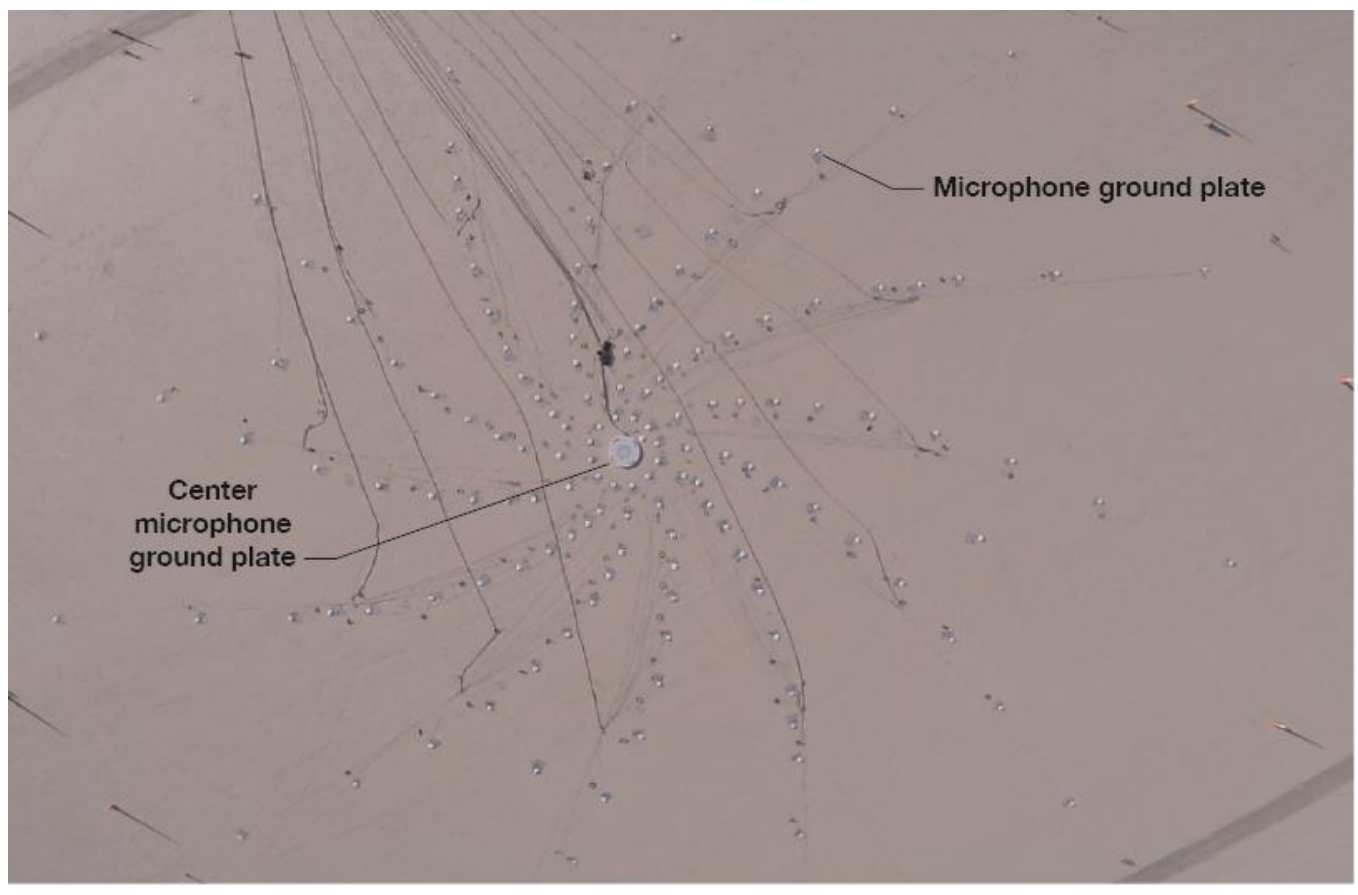

Fig. 1. Aerial view of the ARM microphone array. 


\section{Test Aircraft}

Two GIII aircraft were used as part of the ARM flights. The GIII is a twin-turbofan, swept-wing business jet built by Gulfstream Aerospace Corporation. Two of the NASA GIII aircraft, the SCRAT and the NASA 808 airplane, were used to acquire ARM data. The NASA 808 airplane is primarily used for pilot proficiency training, and the SCRAT is a research aircraft. During the ARM I flights, it was found that the differences in the power generation and utilization between the two aircraft results in the SCRAT having a slightly higher acoustic noise level than the NASA 808 airplane.

\section{A. Subsonic Research Aircraft Testbed}

The SCRAT has been developed as a flight research platform for the purpose of raising the technology readiness level of advanced, environmentally responsible technologies suitable for transport class aircraft [10]. To serve this purpose, the SCRAT has been outfitted with a research quality instrumentation system. The SCRAT power system has been modified to support a power distribution system designed to accommodate the instrumentation and research systems. In addition, the cabin interior includes workstations for researchers and instrumentation engineers to monitor research experiments and aircraft systems. A telemetry capability has been added to the SCRAT, which allows for control room monitoring of critical parameters during envelope expansion flights, and allows for additional ground based researchers to monitor the status of their experiments. The ACTE flaps were installed on each of the SCRAT wings. Installation of the ACTE flaps required the removal of the aircraft Fowler flaps, and the flight and ground spoilers. In addition to the two pilots, a flight-test engineer (FTE) is onboard the SCRAT for every flight in order to monitor the instrumentation system. Figure 2 contains a 3-view of the unmodified SCRAT without the ACTE flaps installed. Figure 3 shows the SCRAT in-flight with the ACTE flaps installed. While the ACTE flaps are installed, the SCRAT flight envelope is limited to Mach 0.75 and 40,000 ft MSL.

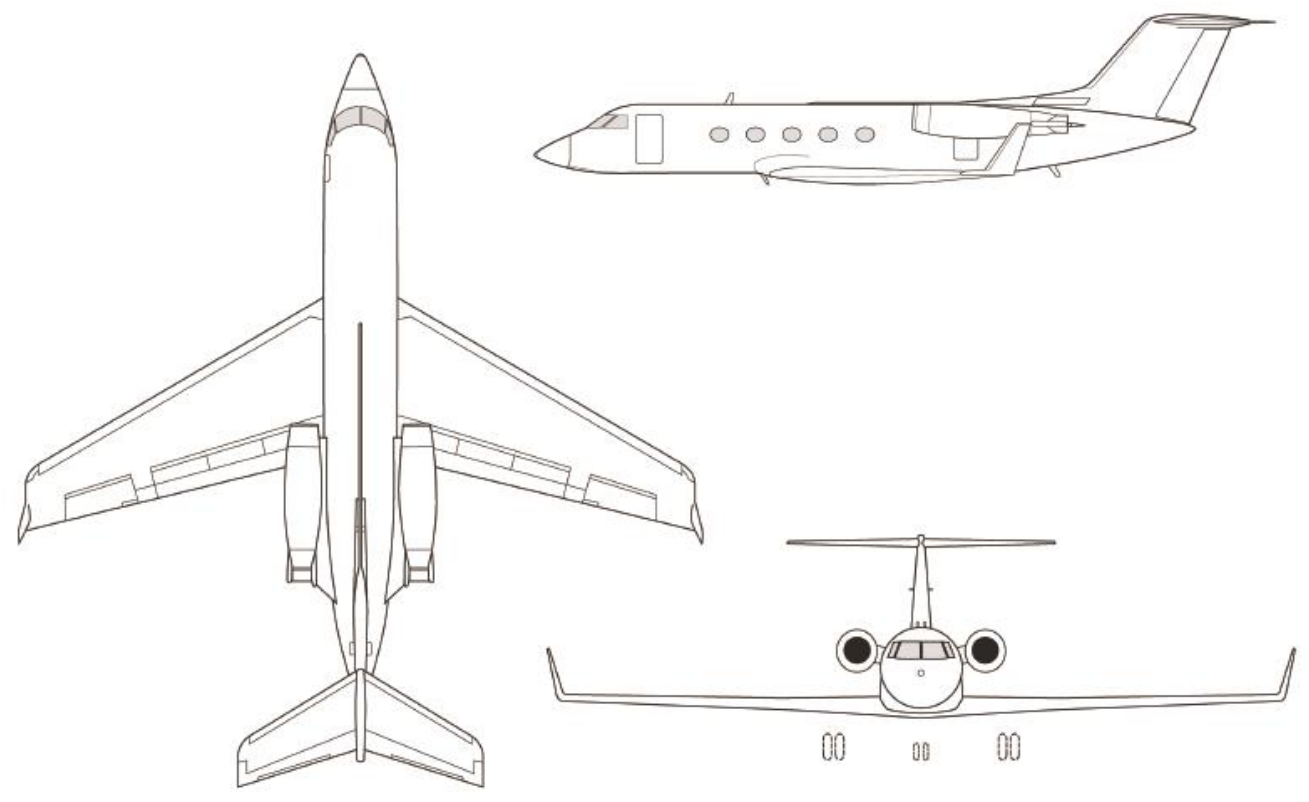

Fig. 2. A 3-view of the SCRAT. 


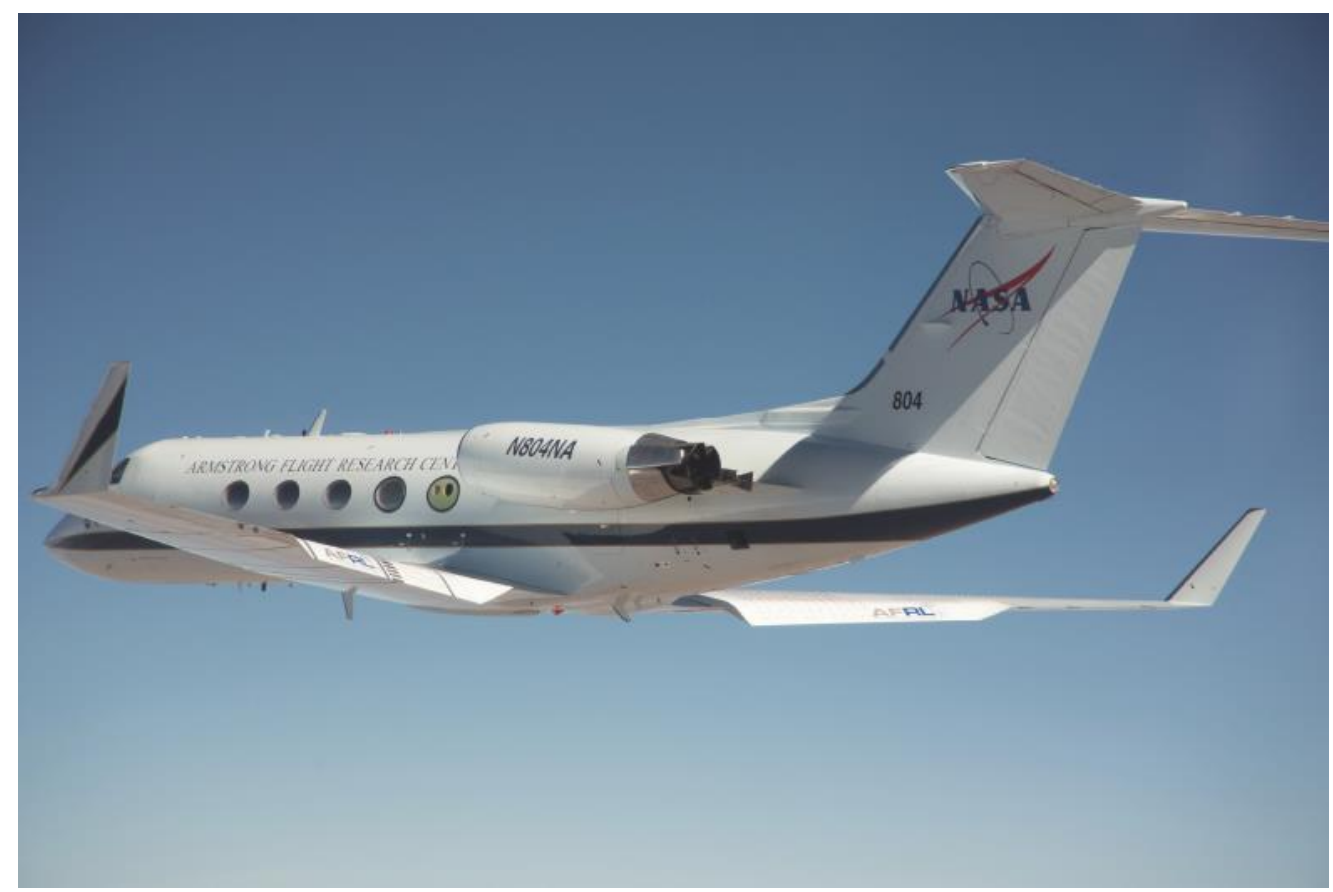

Fig. 3. In-flight image of the SCRAT with the ACTE flaps installed.

The SCRAT yoke mounted tablets, and the FTE displays [10] were modified to support the ARM flights. During the ARM flights, these displays were used primarily to aid with the lakebed research approaches. The pilot display provided information such as altitude and lateral offset to the array centerline in order to assist the pilots in conducting the array over flight. The FTE display was modified to show aircraft state information at various locations relative to the array in order to aid in the processing of quick look information.

\section{B. The National Aeronautics and Space Administration 808 Airplane}

The NASA Armstrong Flight Research Center (AFRC) (Edwards, California) Gulfstream III aircraft tail number N808NA has been designated as a dual use aircraft (Federal Aviation Administration (FAA) Type Certified and Public Use). The FAA Type Certified aircraft configuration is intended to be used for mission management (passenger transport or pilot proficiency). The Public Use configuration is intended to support research projects and would typically be carrying and operating additional research systems, performing safety chase or photo / video chase, and/or carrying experimenters. At any given time, the aircraft can be operated either as Public Use, or FAA Type Certified (operated under 14 CFR part 91 and certified under 14 CFR part 25 Transport Category). During the ARM flights, the NASA 808 airplane was operated as a Public Use aircraft. The NASA 808 airplane, shown in Fig. 4, is essentially a stock GIII aircraft with the addition of a global positioning system (GPS) receiver, which acquires GPS data in support of the ARM flights. 


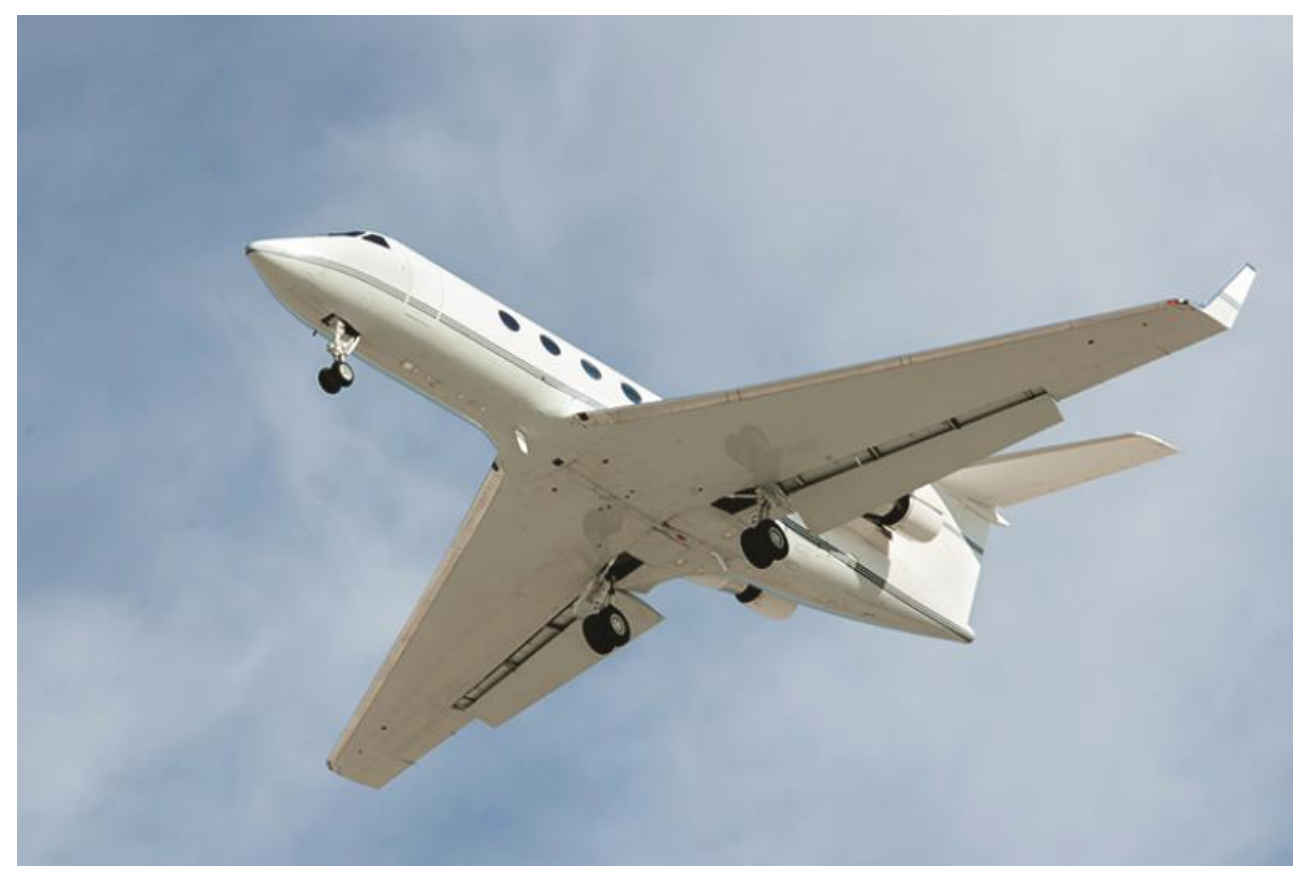

Fig. 4. The NASA 808 airplane in-flight.

\section{Adaptive Compliant Trailing Edge Flaps}

The ACTE flight research project was a joint effort between NASA, the U.S. Air Force Research Laboratory (AFRL) (Wright-Patterson Air Force Base, Ohio), and FlexSys Inc. (Ann Arbor, Michigan) to flight-test the ACTE technology [11]. The objective of the project was to demonstrate a seamless adaptive compliant structural control surface in flight. Wind-tunnel testing and small scale flight tests of the compliant technology were conducted as an initial phase [12], but a full-scale compliant structure required flight-testing to provide data to show the technology could be transitioned to commercial industry. The ACTE flap control surfaces were fabricated and installed to replace both existing Fowler flaps on the SCRAT (Fig. 5). The ACTE flaps were manually actuated on the ground for flight at fixed deflection angles and remained fixed in that position for the duration of the flight. The flaps were flight-tested at deflection ranges of $-2^{\circ}$ and $+30^{\circ}$ ( + signifies down flap deflections).

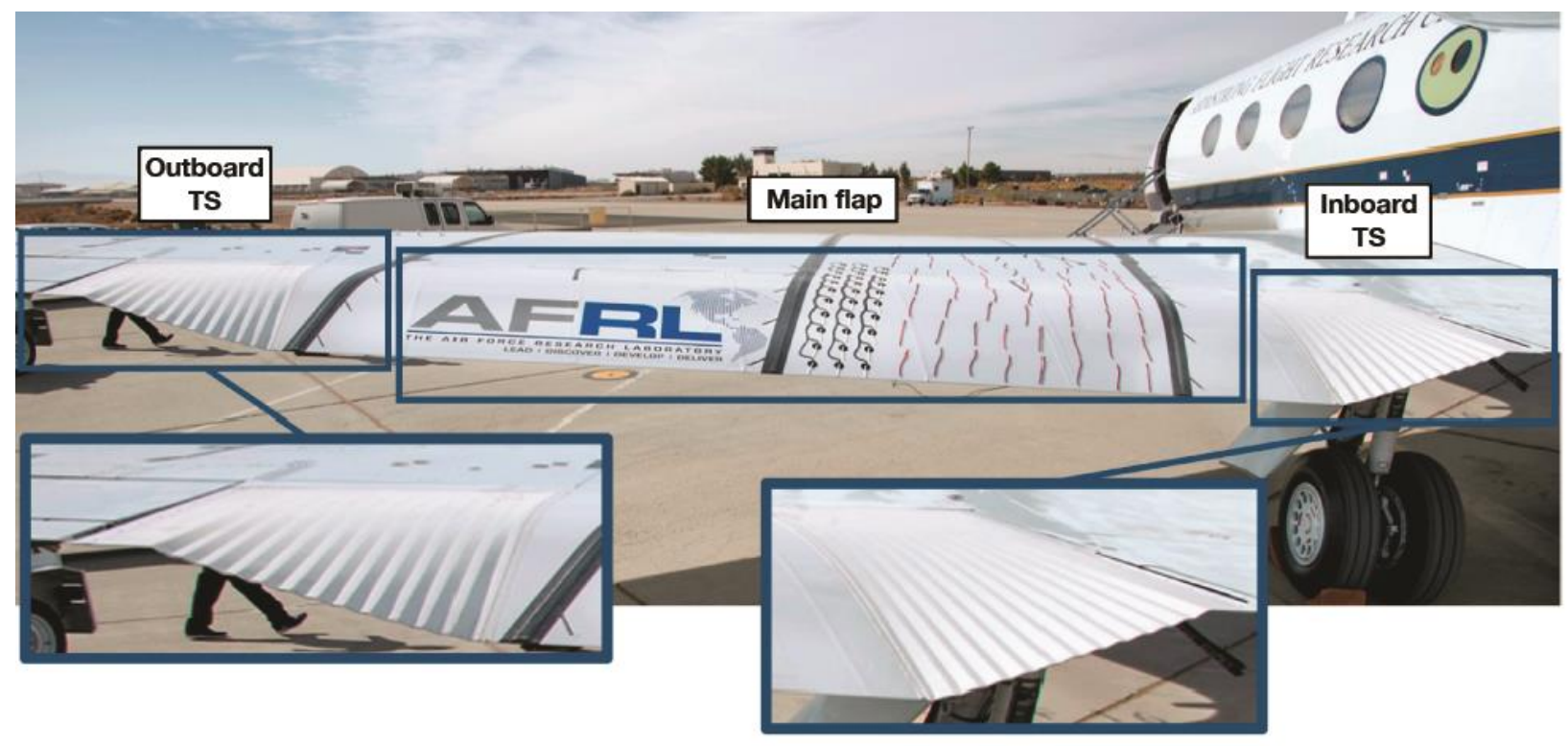

Fig. 5. ACTE main flap and transition surfaces. 
The ACTE flaps had originally been intended to operate solely through an initial series of check-out flights and then be removed from the aircraft prior to the beginning of the ARM project. The ACTE flaps remained on the SCRAT approximately 2.5 years longer than initially intended in order to accomplish a series of follow-on flights, which included the ARM flights. For the ARM flights, the ACTE flaps were flown primarily at high flap deflections and with the aircraft landing gear down. The ACTE flaps experienced greater vibrations when the aircraft landing gear was down, and this greater vibration is an example of one area which required the SCRAT team to constantly monitor the unique, experimental ACTE hardware throughout the ARM flights to ensure no issues affecting flight safety arose. This monitoring took the form of inspections after every flight, real-time monitoring of the ACTE structure internal loads, and post-flight analysis of the ACTE structural loads. No significant issues affecting flight safety arose with the ACTE flaps during the ARM flights, and the ACTE flaps required only relatively minor maintenance.

\section{Landing Gear Noise Reduction Hardware}

The LAGER hardware consists of the MLG fairings, a chevron and batting plate cavity treatment, and a mesh cavity treatment. This hardware was custom designed for flight on the NASA GIII aircraft. A brief overview of each of these items is given in the following sections.

\section{A. Main Landing Gear Fairings}

Figure 6 shows the elements of the MLG fairing. Installation and removal of the MLG fairings on each aircraft can be accomplished in a few hours. Removal of the MLG fairings requires a MLG gear swing since the fared door strut fairing paired with the MLG fairings is swapped out for the production door strut rod. One of the attachments used for the MLG fairings is in the same location where the gear ground safety pin is installed while on the ground to prevent gear retraction. To remain within the allocated time, schedule, and resources of the ARM flight-test campaign, the MLG fairings were not designed to accommodate gear retraction. Gear retraction is physically prevented through the MLG fairings using the aforementioned ground safety pin location as an attachment point. In addition, a physical restraint was placed on the aircraft landing gear handle in the cockpit to provide a physical barrier and visual reminder to the aircrew. This physical restraint was in place when any of the LAGER hardware was installed. The total weight for both the left and right MLG fairings is $90 \mathrm{lb}$.

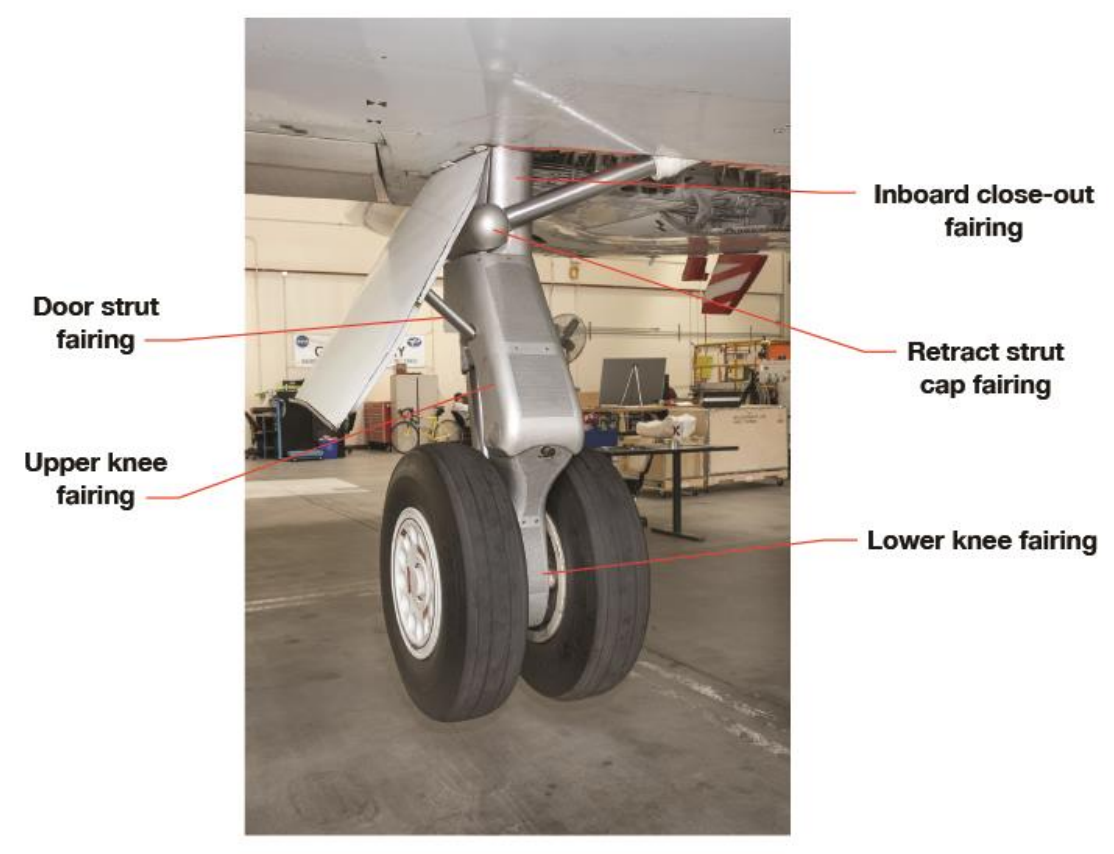

Fig. 6. MLG fairing elements.

\section{B. Chevron and Batting Plate Cavity Treatments}

The LAGER chevron and batting plate cavity treatment, shown in Fig. 7, consists of two elements. The first element is a chevron plate installed on the leading edge of the door cavity. The second element is referred to as a 
"batting plate," which is covered with a noise absorbing acoustic blanket and is installed on the aft wall of the door cavity. To remain within the allocated time, schedule, and resources of the ARM flight-test campaign, the LAGER chevron and batting plate cavity treatment was not designed to accommodate gear retraction. Gear retraction is physically prevented through the installation of a flight safety pin on the MLG. The total weight for both the left and right chevron and batting plate cavity treatments is $8 \mathrm{lb}$.

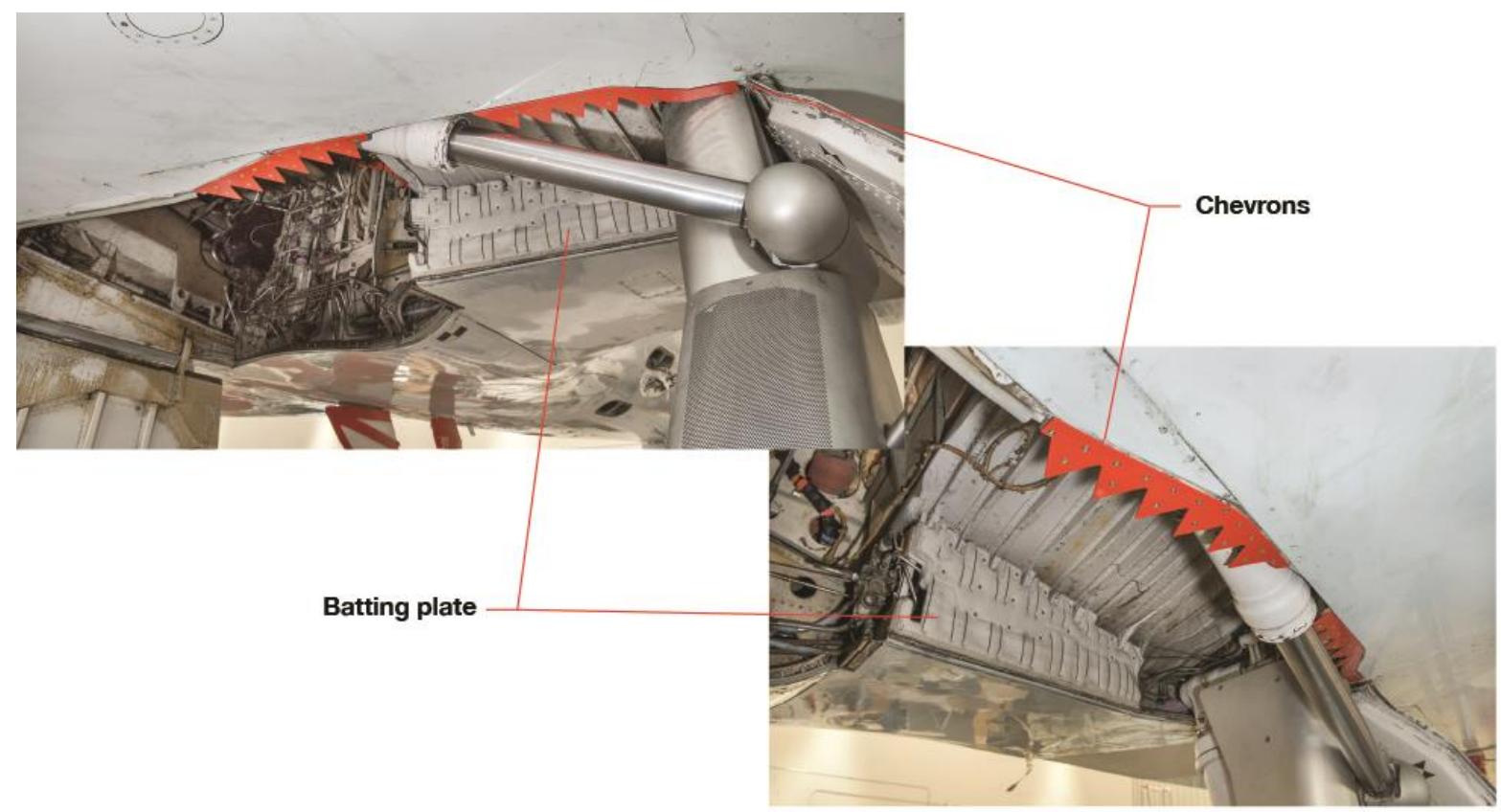

Fig 7. LAGER chevron and batting plate cavity treatment.

\section{Mesh Cavity Treatment}

The LAGER mesh cavity treatment is shown in Fig. 8. The treatment consists of a frame to support a mesh, which is stretched over the door cavity. The LAGER mesh cavity treatment was not designed to accommodate gear retraction. Gear retraction is physically prevented through the installation of a flight safety pin on the MLG. The total weight for both the left and right mesh cavity treatments is $7 \mathrm{lb}$.
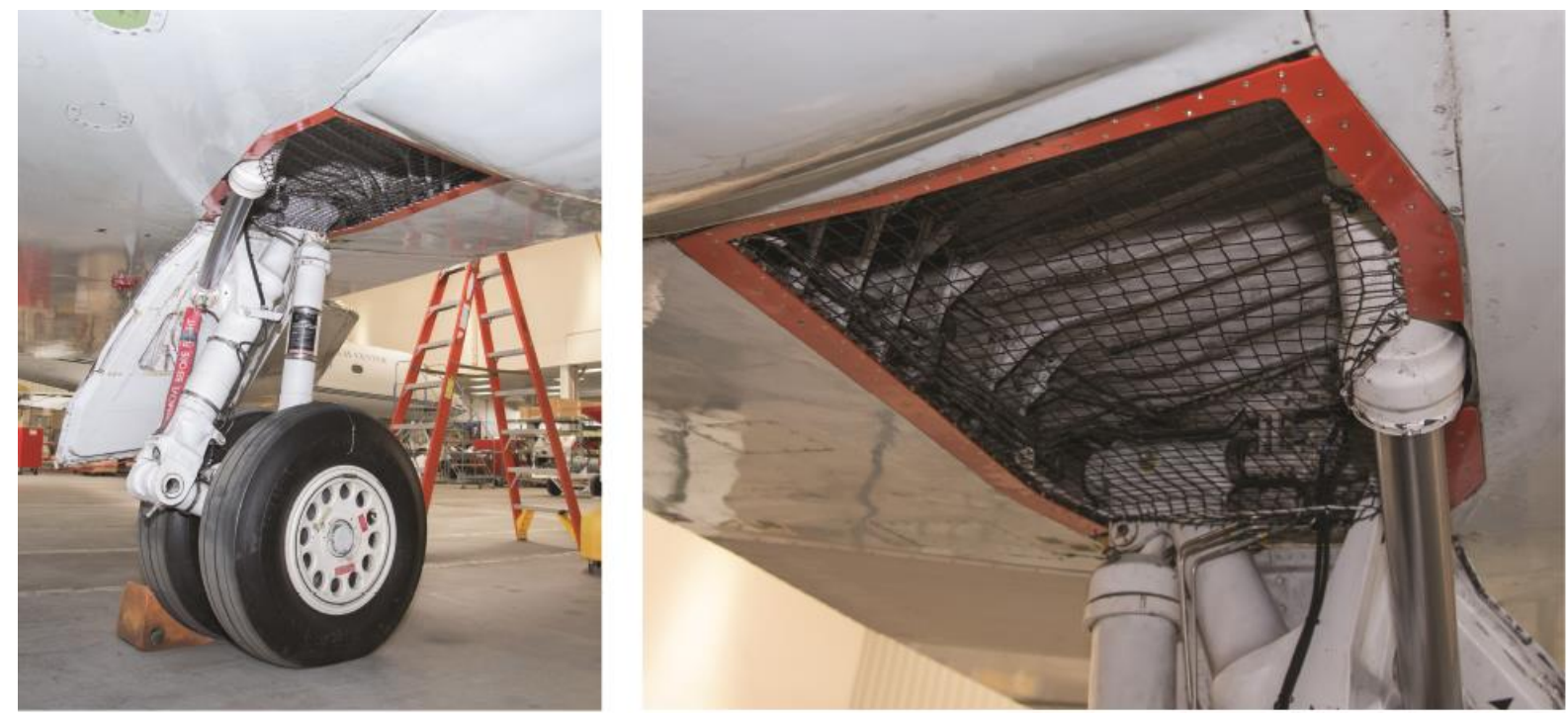

Fig. 8. LAGER mesh cavity treatment. 


\section{Landing Gear Noise Reduction Hardware Design, Manufacturing, Review, Integration, and Flight Clearance}

The effort to prepare the LAGER hardware for flight included: requirements development design, analysis, and manufacturing of the flight hardware. Integration activities took a significant amount of time prior to the initial flight with the LAGER hardware installed. Throughout the whole lifecycle of the LAGER hardware development, an independent review process was in place to ensure the airworthiness of the flight hardware. The last step prior to flying the LAGER hardware over the array and gathering research data consisted of a series of flight clearance tests to demonstrate airworthiness.

\section{A. Requirements Development}

At the start of the project, the LAGER hardware was at a conceptual design stage and was based on conceptual models used to test the concepts in wind tunnels and in computational fluid dynamics (CFD) analysis. Definitive research requirements for the LAGER hardware were not yet written due to the conceptual and developmental nature of the technology. The approach the team took was to heavily include the LAGER principle investigator (PI) in the design of the hardware. The LAGER PI provided inputs on the desired hardware configuration and provided guidance on such things as fairing-hole diameter, how the pieces of the hardware should blend together, and how to streamline the hardware. The extensive experience of the PI with wind-tunnel and CFD analysis of various landing gear noise reduction configurations was invaluable in arriving at an acceptable configuration [3]. What proved most useful was to have the PI sit with the lead designer and quickly adjust the design to meet the noise reduction goals. The PI was able to estimate the predicted noise reduction benefits with a turnaround measured in weeks, and this estimate was used to adjust the designs as the project progressed through the required design reviews.

Airworthiness requirements ensured the LAGER flight hardware was safe to fly on the aircraft. In order to ensure the LAGER hardware would be airworthy for flight on the SCRAT and the NASA 808 airplane, the hardware had to meet the following factors of safety, which are based on AFRC guidelines:

- Ultimate factors of safety:

$\circ \quad+2.25$ for all metallic components,

$\circ \quad+3.0$ for all non-metallic components, and

$\circ \quad$ Fitting factor +1.15 .

The following flight conditions and load factors were used to generate the load cases for which the LAGER hardware had to be analyzed.

Maximum airspeed of 265 knots calibrated air speed (KCAS) (250 KCAS nominal flight limit with a 15 KCAS over speed):

- $\quad$ Altitude range of 0 to $20,000 \mathrm{ft}$ MSL;

- $2 \mathrm{~g}$ inertial load in all three directions;

- $20 \mathrm{~g}$ forward and down inertial loads for hardware attached below the knee joint;

- Gust loading requirement per FAA Federal Aviation Regulation (FAR) 25.345;

- $20^{\circ}$ of yaw;

- Hot conditions of $+200^{\circ} \mathrm{F}$ for lower knee fairings (due to braking influences), all other hardware $+165^{\circ} \mathrm{F}$; and

- Cold conditions of $-65^{\circ} \mathrm{F}$ for all fairings and brackets, thermal factor +1.2 .

In addition to the above airworthiness requirements, additional requirements were placed on the clearances between the tires and the LAGER fairings. The Goodyear Tire \& Rubber Company (Akron, Ohio) Global Aviation Tires databook [13] was used to determine the required tire clearances between the LAGER fairings and the aircraft tires. These clearances are shown in Table 1. One lesson learned is to ensure the required clearances are well understood, well documented, and contain sufficient margin to account for minor discrepancies between the modeled and as-built hardware. The required clearances were not initially calculated correctly and were insufficiently checked in the prototyping stage. These errors required last-minute trimming of the lower fairing and a removal of material in the upper fairing knee area to ensure adequate clearance. 
Table 1. Required tire clearances.

\begin{tabular}{|l|c|}
\cline { 2 - 2 } \multicolumn{1}{c|}{} & $\begin{array}{c}\text { Required } \\
\text { clearance, } \text { in. }\end{array}$ \\
\hline Radial clearance & 1.24 \\
\hline Lateral clearance & 0.60 \\
\hline Clearance from tire rim & 0.25 \\
\hline Shoulder clearance & 0.64 \\
\hline
\end{tabular}

\section{B. Hardware Analysis}

The LAGER fairings were analyzed for a total of 152 different load cases with varying inertial, aerodynamic, and thermal loads. Positive margin was maintained for all metallic components. The lowest margin of safety was +0.00 for the inner bracket (lower strut), knee joint pin, and support fitting to inboard close-out fairing fasteners. The load cases analyzed were considered to be conservative and included worse case load combinations such as: $+20^{\circ}$ yaw at $265 \mathrm{KCAS}$ with a temperature of $-65^{\circ} \mathrm{F}$. The analysis included a $10 \%$ knock down material strength on all thermal conditions. Due to the conservative nature of the LAGER fairing analysis, a simple post-flight visual inspection of the hardware was required, and there was no need to take the hardware apart after flight for a more detailed inspection.

The chevron and supporting hardware (braces, fasteners, et cetera) were found to have high margins of safety with the lowest found to be a margin of safety of 2.48 for the chevron support. The natural frequency for the chevron was examined since it is a partially supported extension. The natural frequencies were found to be high indicating the assembly is stiff with no flutter concerns. A buckling analysis was also performed indicating the load factors are high.

The batting plate load assessment largely relied on an assessment of the attachment structure to carry the inertial loads. The total weight of the plate assembly is approximately $2.6 \mathrm{lb}$, and the structure was analyzed for an inertial load of $15.6 \mathrm{lb}$ or $6 \mathrm{~g}$. The strength of the click-bonds and brackets used to hold the batting plate in place were all found to be high. It was found to be important to perform a 100\% proof test on the bounding strength of brackets and click-bonds in order to ensure the hardware had been properly installed.

A conservative approach was used to assess the aerodynamic load on the net, and that value was found to be small. The mesh itself underwent several pull tests to confirm the material properties. The mesh was installed pre-tensioned to minimize any potential vibration. Analysis of the support structure was shown to be able to withstand a high load capability. In summary, the mesh cavity treatment was cleared by stating that the expected loads are small relative to the structural capability of the support structure.

\section{Hardware Manufacturing}

After the final design review, the large, complex geometry fairing parts were changed from three-dimensional (3-D) printed parts to being manufactured out of aluminum. This last-minute change was made when it became obvious that insufficient material databases existed to flight-qualify the 3-D printed parts. The late change complicated the manufacturing process since the parts were originally designed to be 3-D printed. This change in the manufacturing process resulted in various complex features remaining in the design, which caused difficulties when the parts were manufactured in aluminum. The project weighed the time it would take to redesign the MLG fairings to make them easier to manufacture out of aluminum versus the increased manufacturing complexity and time resulting from the use of a non-optimal design. In this case, the project elected to proceed to manufacturing with a non-optimal design since the time to re-design the parts was considered to be greater than the expected increased manufacturing time.

The main landing gear fairing components were outsourced to various manufacturers. The same manufacturer was used for all of the external outer mold line components, (e.g. the large external fairing components), while the rest of the various components (brackets, fittings, et cetera) were outsourced to several manufacturers. Due to the unique nature of the large outer mold line components, the manufacturer quickly discovered that it would take far longer than initially planned to manufacture each of the components. This additional manufacturing time caused a delay that the project had to absorb. A number of lessons were learned in that the large, complex geometry parts should be manufactured either by a company with relevant experience and/or multiple machines for parallel fabrication or that multiple manufacturers should be used for parallel processing of the complex parts.

The mesh cavity treatment and the chevron and batting plate cavity treatment were manufactured on-site by the AFRC fabrication shop. This choice to manufacture these components on-site proved to be very useful as the fabricators could walk out to the airplane and talk to the designers in person whenever problems occurred. In addition, this choice allowed for the personnel building up the hardware to be the ones doing the initial installation on the aircraft. 


\section{Verification and Validation Testing}

A series of verification and validation tests were performed as part of preparing the aircraft and LAGER hardware for the ARM flights. This testing included fit checks with 3-D printed prototypes of the MLG fairings, tire clearance checks with the flight hardware, landing gear lockout tests, taxi tests, and envelope clearance flights.

\section{Three-dimensional Prototyping}

Prototype parts of the MLG were manufactured using various 3-D printing tools. The parts were fit checked after the Critical Design Review (CDR), which is late in the development cycle as the design should be roughly $90 \%$ finalized at CDR. The fit checks were mainly focused on assessing the fit-up of the parts on the MLG. One critical aspect that was overlooked was conducting a detailed examination of the tire clearances. There was inadequate clearance between the prototype lower fairings and the tires, but the tire clearances were overlooked at the time as the initial focus was on ensuring a proper fit-up on the main landing gear. One lesson learned is to have drafts of the final verification and validation $(\mathrm{V} \& \mathrm{~V})$ tests available for all prototype checks and run the tests with the prototype hardware. Running the draft procedures with the prototype hardware is a quick and early way to iron out issues with the procedures and the design.

\section{Landing Gear Noise Reduction Hardware Clearance Tests}

One important feature of the V\&V testing was to ensure adequate clearance existed between the LAGER fairings and the MLG tires. Clearances between all of the LAGER hardware and the aircraft hydraulic lines, doors, and aircraft structure were examined to ensure there would be no issues in-flight. The clearance testing consisted of installing the LAGER hardware on the aircraft and using a series of fixed width tools to ensure the required minimum clearance existed between the LAGER hardware and the aircraft structure. Figure 9 shows the evaluation of the radial and shoulder tire clearance requirements for one of the MLG positions examined. During the process of the tire clearance checks, it was discovered that the clearances needed to be examined with the MLG strut compressed since the relative distance between the upper MLG fairing and the tires changed as the MLG strut was compressed.

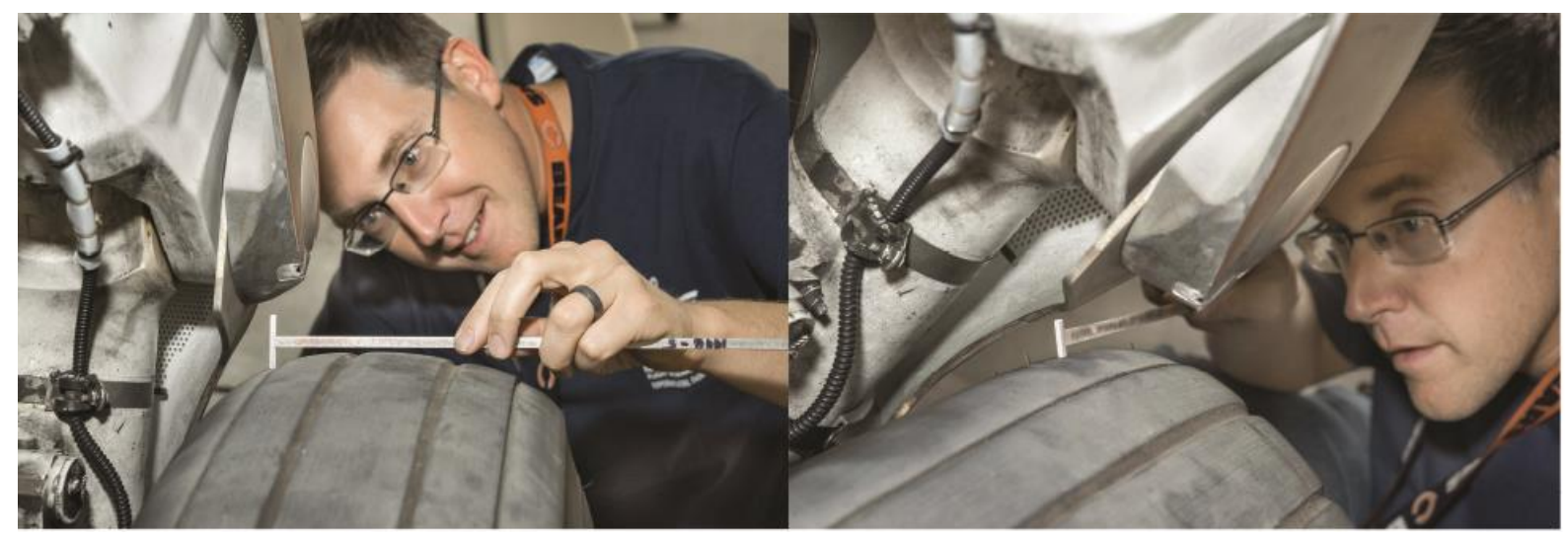

Fig. 9. Evaluation of radial and shoulder tire clearance requirements.

\section{Taxi Tests}

Two taxi tests were performed with the SCRAT aircraft prior to conducting any flights of the LAGER hardware. The first taxi test was conducted without the MLG fairings installed, and the second taxi test was conducted with the MLG fairings installed. These taxi tests were intended to assess if the MLG fairings would result in increased brake and tire temperatures. For the taxi test, the ACTE flap deflection was set to $0^{\circ}$ since this deflection was the lowest aircraft drag configuration. During the taxi tests, the aircrew first accelerated to approximately 110-kn ground speed and then conducted the aircraft anti-skid brake test card which consisted of applying full brakes for several seconds at 90-kn ground speed. The anti-skid brake test was selected to approximate a worst-case brake application scenario and to provide the aircrew with a relatively repeatable test point. Temperature tabs were installed near the brake assembly to monitor maximum temperature. These tabs were selected to change color if they experienced temperatures between $370-480^{\circ} \mathrm{F}$. This temperature range was selected in order to ascertain if the temperature of any part of the brakes approached the tire fuse plug value of $430^{\circ} \mathrm{F}$. A brake temperature approaching the fuse plug value is not necessarily a concern since there is a gap between the brakes and the rubber tires. In addition, a pyrometer was used to measure the brake temperatures measured at the 12 o'clock position on the brake backing plates and tire temperatures measured 
at the 12 o'clock position, halfway up the tire sidewall of both tires before and after the taxi test. Since only two taxi tests were performed, it was difficult to draw any definitive conclusion as to the effect of the MLG fairings on brake and tire temperatures. The two tests were done on separate days. The taxi test without the MLG fairings was done on a day with an approximately $20 \mathrm{kn}$ headwind. The taxi test with the MLG fairings was done on a day with calm winds and an ambient temperature several degrees higher. The timeline and total taxi distances were comparable between the two days. In addition, there were slight differences in technique and timing of brake application by the pilots between the two days.

The actual results of the taxi tests were inconclusive regarding the impact of the fairings on the brake temperatures. Brake and tire temperatures did increase with the MLG fairings installed, but it is unclear whether the increases were due to the MLG fairings shielding cooling air to the brakes or if it was due to the different weather conditions. Table 2 shows the maximum tire sidewall and brake plate temperatures seen during the two taxi tests along with a previously conducted taxi test conducted in support of the ACTE project.

Table 2. Brake and tire temperatures.

\begin{tabular}{|c|c|c|}
\cline { 2 - 3 } \multicolumn{1}{c|}{} & $\begin{array}{c}\text { Max tire sidewall } \\
\text { temperature, }\end{array}{ }^{\circ} \mathbf{F}$ & $\begin{array}{c}\text { Max brake plate } \\
\text { temperature, }\end{array}{ }^{\circ} \mathbf{F}$ \\
\hline Unfaired taxi & 137.4 & 162.4 \\
\hline Faired taxi & 176 & 215.1 \\
\hline ACTE taxi & 181.4 & 437.8 \\
\hline
\end{tabular}

Despite the differing test conditions, the project was allowed to proceed to flight for the following reasons. The maximum tire sidewall temperatures seen during the LAGER taxi tests remained well below the tire fuse plug limit of $430^{\circ} \mathrm{F}$. The LAGER taxi tests results showed peak temperatures well below what the project had seen previously during an ACTE taxi test and deemed acceptable at the time. The brake temperatures decreased fairly rapidly after the taxi tests indicating that the MLG fairings were not retaining heat. The taxi tests were intentionally aggressive in terms of the brake application. Full brakes are never applied during nominal operations, so the taxi tests are conservative in nature. The pilots typically apply the brakes sparingly during landing and the anti-skid is rarely engaged. The project also continued to monitor the temperature tabs throughout the LAGER flights to ensure there was no undetected cooling issues.

\section{Landing Gear Noise Reduction Hardware Envelope Expansion Flights}

Prior to the first array overflight of the aircraft with the MLG fairings or cavity treatments installed, the LAGER hardware had to be cleared in-flight from an airworthiness standpoint. This clearance was conducted through several envelope expansion flights. Two flights were initially conducted with the SCRAT to clear the LAGER hardware with the ACTE flaps installed. Two separate flights were required since the chevron and batting plate cavity treatment could not be cleared on the same flight as the mesh cavity treatment. The first flight was conducted with the MLG fairings and mesh cavity treatment installed. The second flight was conducted with the MLG fairings and chevron and batting plate cavity treatments installed. For both of the initial SCRAT clearance flights with the ACTE flaps installed, the ACTE flaps were set to $0^{\circ}$. The project was able to show through analysis of existing CFD that clearing the LAGER hardware at all of the ACTE flap settings was not required since little cross-flow exists around the landing gear, and any cross-flow is not significantly affected with increasing ACTE flap deflection. Clearing the LAGER hardware at an ACTE flap deflection of $0^{\circ}$ also allowed the clearance test points to be done at a significantly higher airspeed, 250 knots indicated airspeed (KIAS), and dynamic pressure than would be seen during normal ARM flight operations. As a result, the LAGER clearance flights subjected the LAGER hardware to higher structural and aerodynamic loads than would be required during nominal operations. The MLG fairings and the mesh cavity treatment were flown on the NASA 808 airplane in order to clear the LAGER hardware for operation on a GIII aircraft with the fowler flaps installed. The purpose of this flight was to confirm there was no aerodynamic interference between the production fowler flaps of the aircraft and the LAGER hardware. This clearance flight on the NASA 808 airplane allowed for the LAGER hardware to be flown on both the NASA 808 airplane and the SCRAT with the production fowler flaps installed. The aircraft configurations and test point airspeeds flown as part of the envelope expansion flight are summarized in Table 3. 
Table 3. Summary of envelope expansion test points and airspeeds.

\begin{tabular}{|c|c|c|c|c|}
\hline $\begin{array}{c}\text { Flap } \\
\text { configuration }\end{array}$ & $\begin{array}{c}\text { Flap } \\
\text { deflection(s) }\end{array}$ & $\begin{array}{c}\text { Test point } \\
\text { airspeed, } \\
\text { KIAS }\end{array}$ & $\begin{array}{c}\text { LAGER } \\
\text { MLG fairings } \\
\text { installed }\end{array}$ & $\begin{array}{c}\text { LAGER } \\
\text { MLG cavity } \\
\text { treatment } \\
\text { installed }\end{array}$ \\
\hline Fowler flaps & $0,10,20,39$ & $170,200,220$, & Yes & Mesh \\
\hline ACTE flaps & 0 & 200,250 & Yes & $\begin{array}{c}\text { Chevrons and } \\
\text { batting plate }\end{array}$ \\
\hline ACTE flaps & 0 & 200,250 & Yes & Mesh \\
\hline
\end{tabular}

All of the test points on the envelope expansion flights required safety chase aircraft, and a NASA control room was staffed with a flight monitor to assist in the event of any aircraft or LAGER hardware issues.

The envelope expansion test points and maneuvers are listed below in Table 4 in the order in which they were flown. Figure 10 shows the airspeeds and flap deflections flown as part of the envelope expansion test points. The envelope expansion test points were all done at a higher airspeed and dynamic pressure than required for the ARM test points in order to ensure the hardware was adequately checked out in-flight prior to commencing the flights.

Table 4. Envelope expansion test maneuvers.

\begin{tabular}{|l|}
\hline Takeoff \\
\hline 10,000 foot test points \\
-Controllability check \\
-Sideslip to bank check \\
\hline 20,000 foot test points \\
-Wind-up turn to $\sim 1.5 \mathrm{~g}$ (in reality $\sim 50^{\circ}$ bank turn) at 200 KIAS \\
-Level acceleration to the maximum airspeed \\
\hline 10,000 foot test points \\
-Wind-up turn to $\sim 1.5 \mathrm{~g}$ (in reality $\sim 50^{\circ}$ bank turn) at 200 or 170 KIAS \\
-Level acceleration to the maximum airspeed \\
-Controllability check \\
-Sideslip to bank check \\
\hline Landing
\end{tabular}

Note: Wind-up turns and level accelerations repeated for each Fowler flap deflection and conducted once for ACTE $0^{\circ}$. 


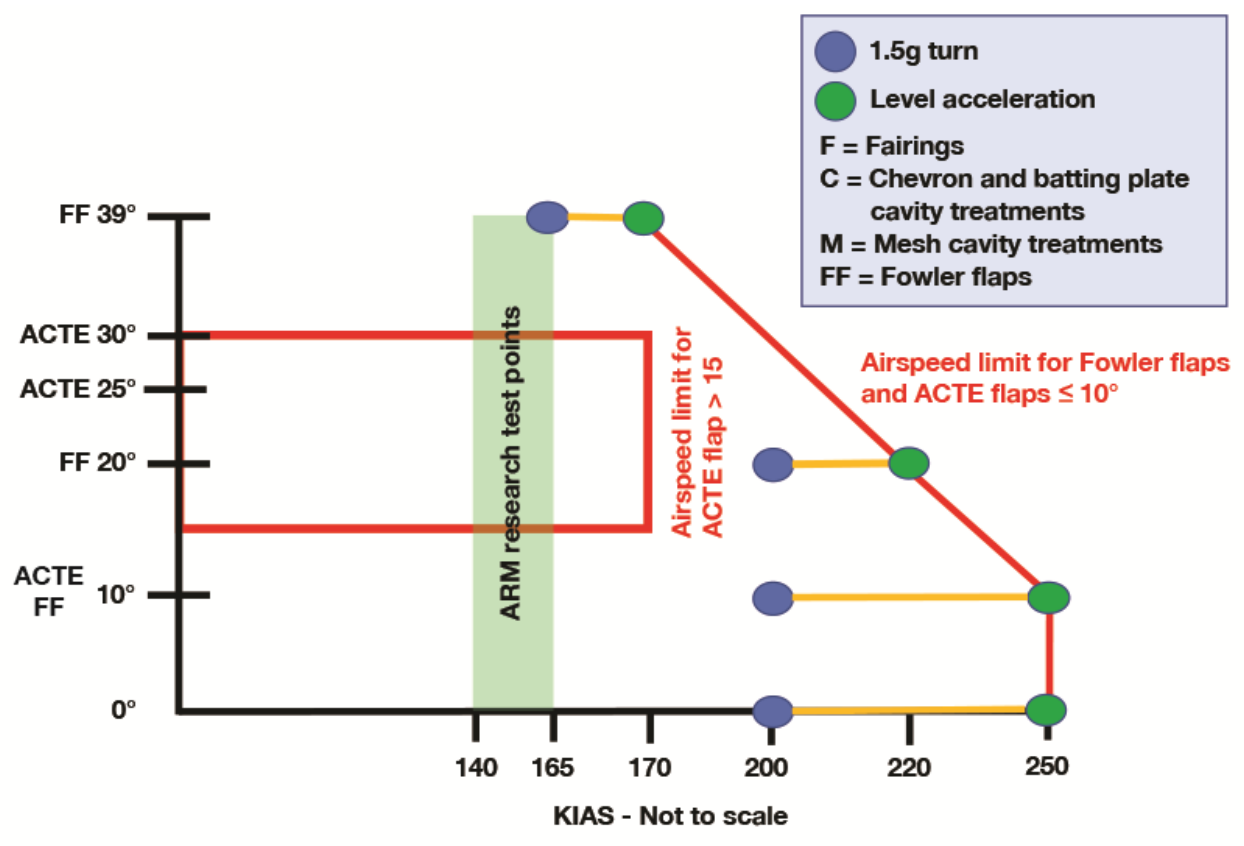

Fig. 10. Envelope expansion airspeeds and flap deflections.

\section{Acoustic Research Measurements Field Operations}

The field operations required to support each of the three ARM flight phases required an extensive amount of planning and coordination. To prepare for the large-scale equipment deployments, many hours were spent planning logistics, coordinating with non-NASA organizations, and procuring the required ground support equipment (GSE). This section summarizes the ARM Field Operations including the GSE, microphone array deployment and surveying, weather measurements, small unmanned aircraft system (sUAS) operations, and staffing considerations.

\section{A. Acoustic Research Measurements Field Operation Location}

The microphone array for ARM I and ARM II was set up on Rogers Dry Lakebed on EAFB. Specifically, the array was set up on the approach end of Runway 18L. The lakebed location used for ARM I and ARM II is occasionally inaccessible in the ARM III timeframe due to flooding from seasonal rains. As a result, the project elected to mitigate the risk of seasonal rains impacting the test by relocating the test site to higher ground. The microphone array location was moved approximately half a mile to the west of the lakebed location and placed on the EAFB inactive North Base runway. For all three ARM test windows, the site selection was driven by the requirement to have a test site isolated from air traffic and extraneous noise. As can be seen in Fig. 11, the array location selected for ARM I and ARM II had the added benefit of being placed at the tip of a large arrow located on the runway which aided the pilots in lining up over the array centerline.

\section{B. Microphone Array Deployment}

The main microphone array is $250 \mathrm{ft}$ in diameter and consists of 185 microphones. Forty-nine of these microphones are located on the center plate, while the remaining microphones are situated on plastic ground boards. The location of each ground board was identified using a hand-held GPS-based surveying device and then marked with a ten-inch stake and water based spray paint. The center of each stake head was marked with a drill to aid in surveying. The paint markings include a half-inch dot for the sighting hole on the ground board, as well as a circle outlining the edge of the ground board. The location of each microphone was surveyed by the EAFB office of the National Geospatialintelligence Agency and NASA personnel. The main array is supplemented by five certification microphones. Four of the certification microphones were located equidistance apart and placed approximately $330 \mathrm{ft}$ from the center of the array; the fifth is on the center plate of the main array.

Time before and after each flight had to be allocated to uncover and cover each microphone in order to minimize any damage due to dust, moisture, or animals. The 49 microphones on the center plate were covered with a large 
aluminum plate at the end of each day. All of the main array microphones were covered with a small cone and a bat weight at the conclusion of each day.

\section{Ground Support Equipment}

A large amount of GSE was required to be placed on the lakebed in order to support the ARM flights. An overview of GSE layout for ARM I and II is shown in Fig. 11. Figure 12 shows a portion of the GSE layout directly next to the microphone array for ARM I and II as seen from the SCRAT during a practice array overpass. The data recording equipment was located inside the trailer referred to as the "data van," while miscellaneous ground support equipment such as tables, chairs, radios, tents, safety equipment, and spill kits were stored in the "storage trailer" while not in use. The data van, where most of the field crew sat during the flight, was approximately $125 \mathrm{ft}$ from the edge of the main array. There were several generators used to power the test equipment: five were used by the data van, one was used by the aerostat, and one was set aside as a spare. The generators sat in large plastic spill trays and were required to be at least five feet away from any object, including other generators. Fuel for the generators was stored in a large covered total containment cabinet far removed from vehicular traffic and ignition sources. The generators near the data van were shielded with large cubical walls to reduce the amount of generator noise which reached the main array. The cubical walls were folded up and laid on their sides at the conclusion of each day, and sand bags were placed on top of the cubical walls to prevent them from being damaged in high winds. Two portable lighting towers were used to light up the array during the pre-dawn set-up hours and were turned off after sunrise.

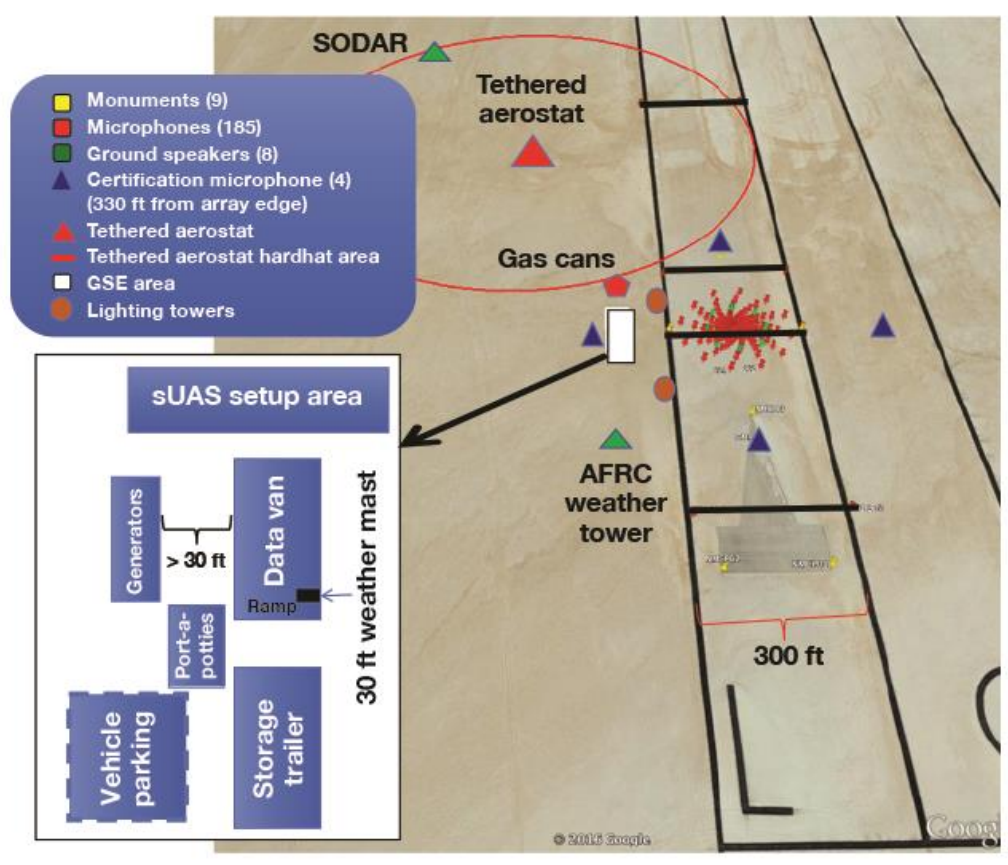

Fig. 11. Diagram of ARM ground support equipment layout. 


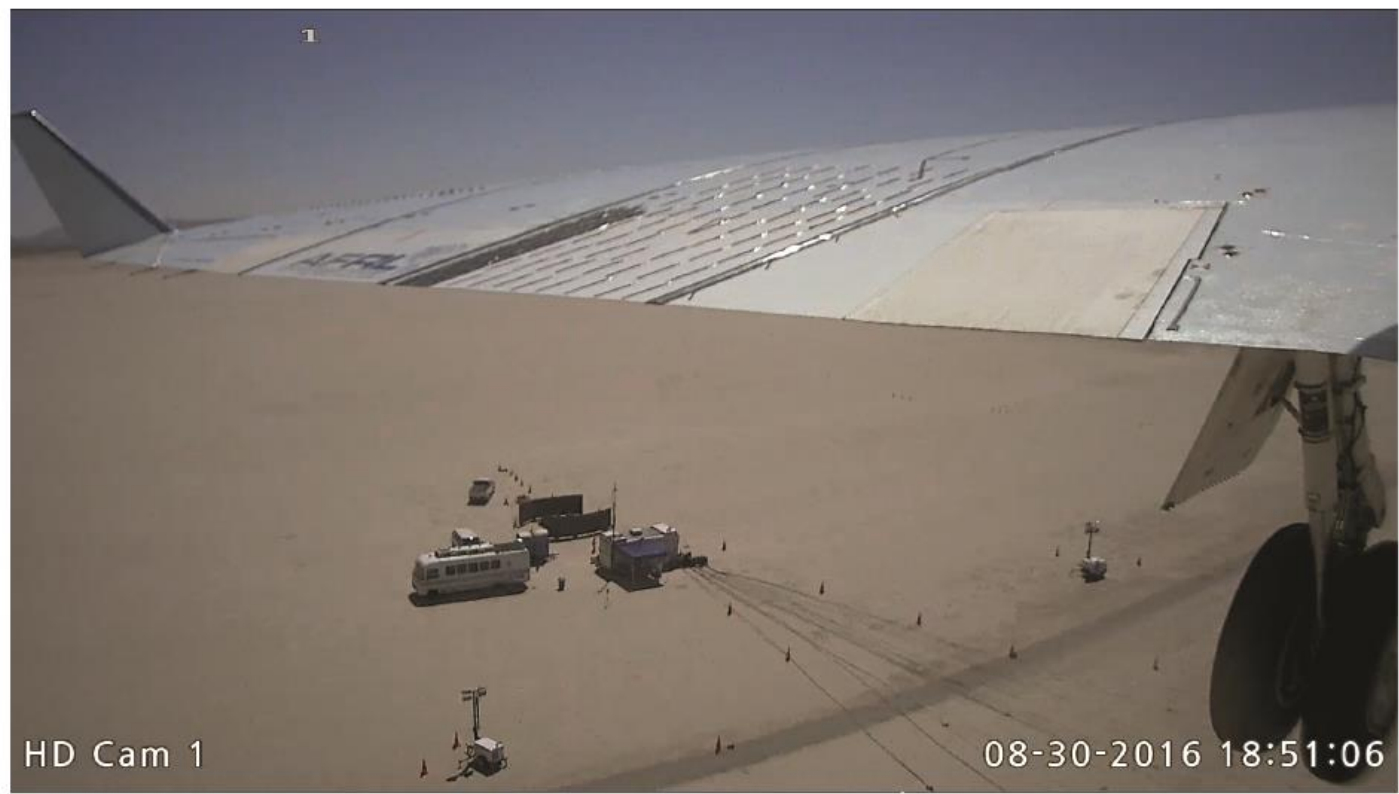

Fig. 12. Data van, storage trailer, and generators as seen from the SCRAT.

\section{Planning and Logistics}

An extensive amount of planning and coordination went into each of the ARM flight campaigns to ensure successful field operations. The test site was located several miles from AFRC in a controlled movement area, which increased the logistical complexity. Close coordination between the LaRC and AFRC team members was key to the planning effort. Initial discussions between team members laid the ground work for requirements, test point priorities, testing schedule, and miscellaneous logistics such as equipment shipping and personnel training.

Extensive coordination occurred between NASA and multiple organizations on EAFB in order for the ARM field operations to be successful. Permission to use the lakebed runway was granted by the EAFB Air Field Management and Civil Engineering groups. The array and ground support equipment layout and survey markers were approved by EAFB Air Field Management and Environmental Management; the use of the aerostat and the sUAS were approved by Airspace Management and Frequency Management. The surveying work was completed with the EAFB office of the National Geospatial-intelligence Agency with the assistance of NASA personnel. EAFB Airspace Management approved the use of the airspace, and this group briefed the general concept of operations to the Operations Group Commander who gave the final approval to conduct the ARM operations on EAFB. In addition, there was regular coordination to de-conflict the airspace or frequencies with other EAFB organizations on a daily basis during the tests.

As previously mentioned, the remote location and the restricted access to the test site posed many logistical challenges. AFRC personnel were required to obtain a level III flight line driver's license and a flight line access badge in order to gain access to the test site, which included the ability to escort visiting personnel to the test site. Location specific training concerning heat stress and wildlife awareness was given to every individual involved in field operations. Given the remote location, waste management, first aid, and emergency response situations were given significant considerations; emergency plans were formed, porta-potties were rented. In addition, fire extinguishers, eye wash stations, a spill kit, a first aid kit, and large amounts of water were purchased.

Future testers should note that this amount of coordination, complicated logistics, and planning is to be expected for any type of field operation and requires a substantial amount of time and labor; readers are directed to "An Overview of Lessons Learned from Sonic Boom Flight Research Projects Conducted by NASA Armstrong Flight Research Center" [14] for a detailed explanation of coordination and logistical planning for similar efforts.

\section{E. Weather Restrictions and Equipment}

The quality of acoustic data gathered during testing is highly weather dependent [15]; specifically, air temperature and humidity level can significantly impact the frequency range of the acoustic data acquired. For the ARM flights, temperature, humidity, and wind restrictions, which are detailed below, were put in place in order to maximize data quality and minimize the magnitude of the required atmospheric corrections. Restrictions on temperature and humidity 
for the ARM flights are shown in Fig. 13. Operation outside of these restrictions was permissible with the concurrence of the LAGER PI.

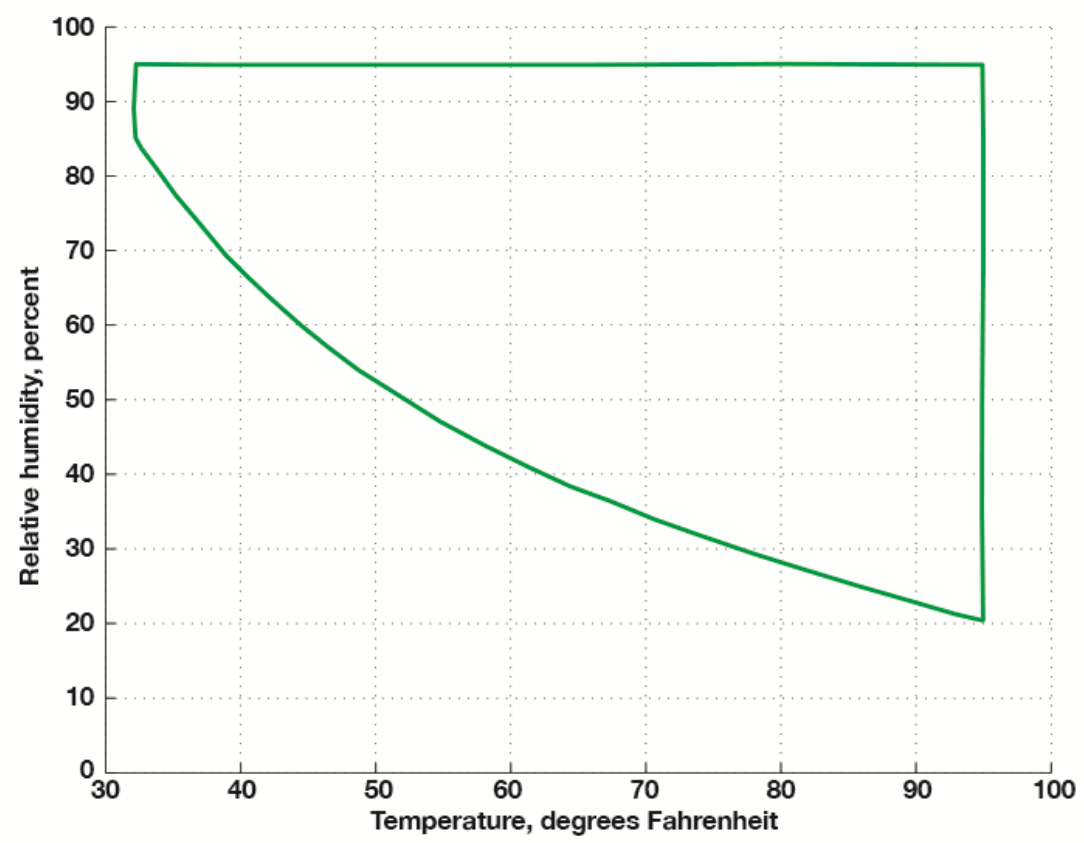

Fig. 13. Temperature and humidity restrictions.

Wind restrictions were in place in order to maximize the data quality. The wind limits are stated below:

- Maximum wind speed $<13 \mathrm{kn}$,

- Average wind speed $<10 \mathrm{kn}$,

- Maximum crosswind $<9 \mathrm{kn}$, and

- Average crosswinds $<6 \mathrm{kn}$.

Due to the importance of the weather to the quality of the acoustic data acquired, several weather instruments were utilized to record and monitor the critical weather parameters during the test [16]. The weather equipment consisted of two weather towers, a mini-sonic detection and ranging (SODAR), and a tethered aerostat.

One of the weather towers was mounted approximately $30 \mathrm{ft}$ above the ground on the data van, and allowed the team to monitor the weather conditions at the test site in real time. The second weather tower was placed near the edge of the microphone array and was approximately $10 \mathrm{ft}$ tall. Both towers recorded temperature, relative humidity, wind speed, wind direction, and atmospheric pressure.

For ARM II and III, a mini-SODAR system was deployed at a location near the tethered aerostat to acquire wind data up to $550 \mathrm{ft}$ in $30 \mathrm{ft}$ intervals. The mini-SoDAR served as a wind profiler, which measures the Doppler shift of sound waves influenced by factors such as atmospheric mixing and particulate matter within the atmosphere. The mini-SODAR was deployed prior to the beginning of the test window and remained in place throughout the flights. The mini-SODAR was an addition after ARM I since the tethered aerostat instrumentation did not provide reliable wind data.

The tethered aerostat (Fig. 14) was used to gather temperature, barometric pressure, and humidity data to complete the weather profile needed during post-processing. The aerostat is filled with 255 cubic feet of Helium and is approximately $15 \mathrm{ft}$ long and $6 \mathrm{ft} 8$ inches in diameter when inflated. The cable and winch assembly were truck mounted allowing for all of the aerostat equipment to be removed from the lakebed at the end of a test day. The aerostat was placed approximately $800 \mathrm{ft}$ from the edge of the microphone array in order to be away from the aircraft flight path and to eliminate the risk of a sonde departing the cable and landing on sensitive equipment during aerostat operation. A hard hat area of $630 \mathrm{ft}$ around the aerostat was marked with large cones and enforced. 


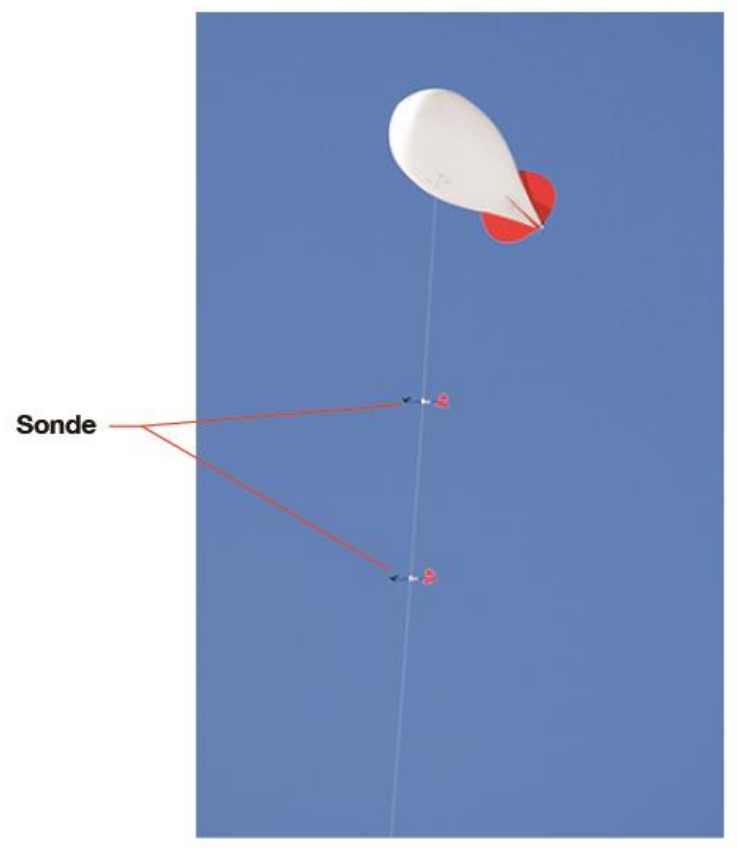

Fig. 14. Tethered aerostat.

\section{F. Small Unmanned Aircraft System Operations}

In order to fully characterize the acoustic environment and to aid in correcting the acoustic data for atmospheric effects, a series of reference tones was broadcast over the center of the array at varying altitudes. An s1000 DJI (Shenzhen, China) Octocopter (Fig. 15) was used to suspend a speaker over the array at multiple altitudes in order to provide the airborne reference tones for the array at the beginning and end of each test day. The calibration was performed prior to the first array overflight and immediately after the last array overflight due to the significant weather changes experienced during the test window. The speaker on the sUAS was connected to a small MP3 player that cycled through a series of known tones. The sUAS dwelled at several altitudes ranging from $100 \mathrm{ft}$ to $350 \mathrm{ft}$ long enough for each pure tone to be played through the speaker. Additionally, the sUAS was equipped with a GPS receiver to allow the test team to compare the actual location of the sUAS to the array. Post-processed GPS data provided the team with a more detailed beam-forming calibration. The sUAS operations were restricted to daylight hours only and had a wind limit of $26 \mathrm{kn}$. 


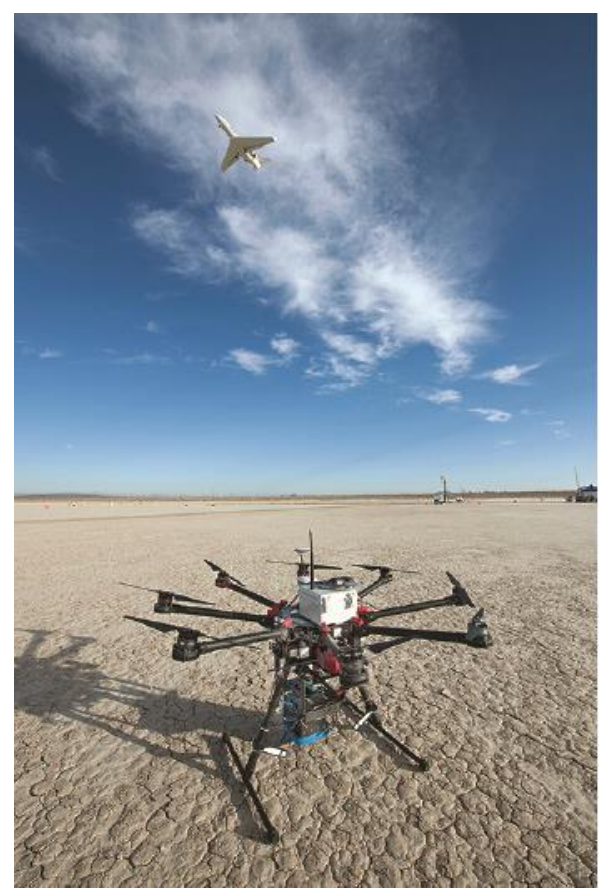

Fig. 15. sUAS used for ARM microphone array calibration.

\section{G. Acoustic Research Measurements Field Operations Staffing}

ARM field operations required a team of personnel at the microphone array site working in close coordination with the aircrew in order to be successful. Field personnel included microphone array operators, the LAGER PI, a field controller, a meteorologist and aerostat assistant, a sUAS pilot and a sUAS ground control operator, and the lakebed controller. Additional personnel were typically on-site for training purposes or when additional help was needed for physical tasks such as setting up the microphone array.

The field team learned several lessons during ARM I related to staffing which greatly improved operations during subsequent deployments. During ARM I, the field crew was minimally staffed with little cross-training and few to no backup personnel. For example, it was common for the roles of field controller and lakebed controller to be fulfilled by the same person. Several people became seriously ill during ARM I potentially due to the strain of supporting early morning operations multiple days a week. These illnesses placed even greater strain on the rest of the test team to cover their roles. For ARM II, the project made a concerted effort to add additional personnel and to cross-train them so they could fulfill at least two roles. The number of personnel available to serve as lakebed controller, field controller, and aerostat operator doubled for ARM II, and the majority of these people were cross-trained in two of these roles. These changes paid off in that no personnel became seriously ill during ARM II, and the team was quickly able to adjust when personnel were unable to participate in the test of the day for various reasons. All of the field operations personnel felt that the staffing changes made for ARM II improved the field operations and greatly enhanced safety.

\section{Acoustic Research Measurements Flight and Ground Operations}

This section describes in detail the ARM flight and ground operations. The ARM flight day operations are described along with the research test point requirements and the flight-test points.

\section{A. Acoustic Research Measurements Flight Day Operations}

ARM I, II, and III flights were all conducted in the same manner. At a high level, the flights consisted of the SCRAT and the NASA 808 airplane overflying the acoustic array in various aircraft configurations and airspeeds to acquire research data. Considerable planning went into placing the aircraft at the desired configuration and test point and in gathering the acoustic data.

Flight and ground operations typically began very early in the morning. Takeoff occurred as close to sunrise as possible in order to ensure that winds, temperature, and humidity remained within limits. The ground operations crew would typically arrive at the array site 2-3 hours prior to the aircraft taking off in order to begin preparing and calibrating the array for data collection. As part of the morning operations, a tethered aerostat was set up and operated 
near the array site, and data from a mini-SODAR system were collected. The tethered aerostat, mini-SODAR, and a weather mast on the data van were used to ascertain if the weather would be acceptable for the operations of the day. The sUAS array calibration would typically occur a few minutes prior to the first aircraft array overflight. Immediately after the sUAS array calibration flight, the ground speakers would perform a separate calibration protocol.

During the ARM flights, the aircraft lead operations engineer served as a flight monitor and sat in a control room at AFRC. The flight monitor responsibilities included monitoring the overall progress of the mission and serving as additional ground based help in the event of an aircraft emergency. At the array site, the lakebed controller role was filled by a senior AFRC representative who handled all communications with the aircraft. The lakebed controller was responsible for the overall test point execution and for providing any feedback from the LAGER PI to the aircraft crew regarding the data quality.

Figure 16 shows a global view of the test setup and key points along the SCRAT flight-path. For ARM I and II, the array was set up on the EAFB Rogers Dry Lakebed on the approach end of Runway 18L. For ARM III, the array was set up on the approach end of EAFB North Base Runway 24. There are five geographic locations of data collection interest referenced to the center of the array.

- $\quad \mathrm{T} 0$ is a line perpendicular to the flight path of the aircraft when the aircraft is lined up for an approach to the runway and is approximately 20 seconds prior to over-flight of the array. This location is of interest because the microphone array operators need approximately 20 seconds to start the recording with sufficient time to ensure the over-flight is captured. Highway 58 is approximately 1.1 miles north east and approximately 20 seconds of flight-time from the center of the array for the lakebed location. The pilots would typically call when they were passing T0.

- $\mathrm{T} 1$ is a line perpendicular to the flight path of the aircraft located $500 \mathrm{ft}$ upstream of the microphone array. $\mathrm{T} 1$ is the beginning of the acoustic and aircraft data collection which is of most interest.

- $\quad \mathrm{T} 2$ is a line perpendicular to the flight path of the aircraft located at the center of the microphone array. $\mathrm{T} 2$ is the targeted test point for each pass.

- $\quad \mathrm{T} 3$ is a line perpendicular to the flight path of the aircraft located at $200 \mathrm{ft}$ down the runway from the center of the microphone array. T3 represents the typical end of the acoustic and aircraft data collection of the most interest.

- T4 is a line perpendicular to the flight path of the aircraft located $1,000 \mathrm{ft}$ down the runway from the center of the microphone array. The pilots were asked to delay their pull-up till after T4 in an attempt to gather additional airframe acoustic noise between T3 and T4.

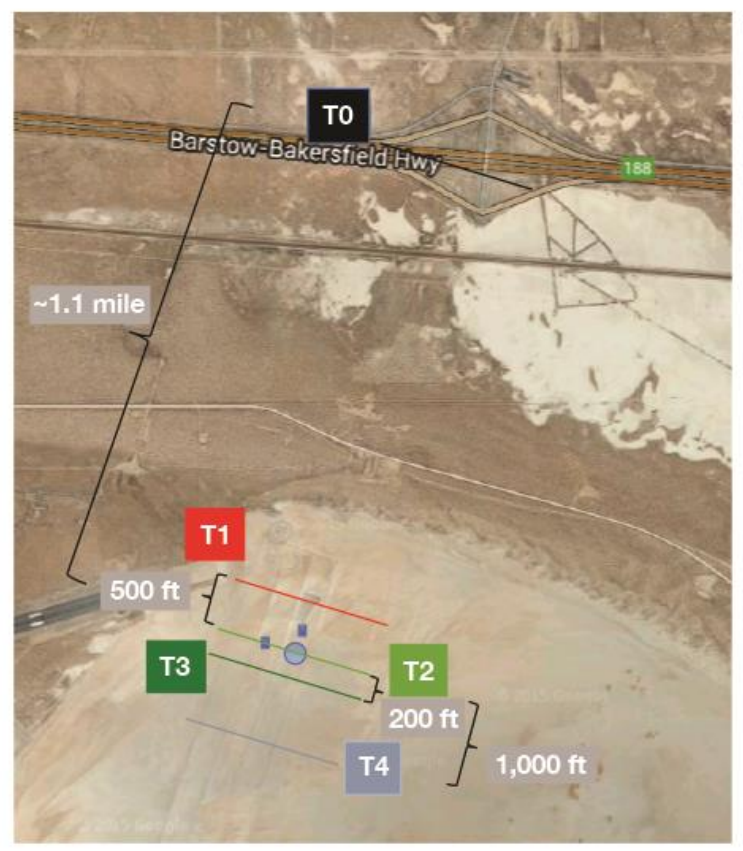

Fig. 16. Overview of the ARM test. 
The flight operations proceeded in the following manner. After takeoff, the pilots configured the aircraft for the first test point and lined the aircraft up for a straight and level approach over the microphone array in order to adjust their instrumentation as needed to achieve the desired $350 \mathrm{ft}$ and $0 \mathrm{ft}$ lateral offset at $\mathrm{T} 2$, which is the center of the array. As the pilots pass T0, they called over the radio, and the array data acquisition operator began the array data collection. The pilots would then fly the aircraft over the microphone array at the desired altitude and airspeed. After each configuration change, the pilots practiced the approach from altitude on the downwind leg. This practice approach was used to adjust the technique for the research pass. While circling back around for the next pass, the FTE called out the aircraft altitude, airspeed, lateral deviation, and time at T1, T2, and T3. The array operators used the aircraft information at T1, T2, and T3 to perform a quick-look analysis of the acquired data to determine if the data were acceptable and if any guidance needs to be given to the pilots to improve the quality of the data. The targeted altitude, lateral offset, airspeed, and throttle setting at T2 is shown in Table 5. Starting partway through ARM II, the FTE sent an image of their display of the aircraft information at T1, T2, and T3 via text messaging while still calling out just the information at $\mathrm{T} 2$ over the radio. This change allowed for a faster assessment of the quality of the pass and significantly reduced the radio communications. The test team stepped through each of the planned test points for the day until the weather conditions were out of limits, all planned test points were accomplished, or the aircraft reached a pre-determined minimum fuel state. The pilots spent much of the first half of the ARM I flights trying different approaches to flying the ARM array overpasses before arriving at a repeatable approach.

Table 5. ARM test point.

\begin{tabular}{|l|c|c|}
\cline { 2 - 3 } \multicolumn{1}{c|}{} & Nominal & Tolerance \\
\hline Altitude & $350 \mathrm{ft}$ & $+/-50 \mathrm{ft}$ \\
\hline Offset & $0 \mathrm{ft}$ & $+/-35 \mathrm{ft}$ \\
\hline Airspeed, KIAS & $140,150,165$ & $+/-5 \mathrm{kn}$ \\
\hline Throttle setting & Ground idle & N/A \\
\hline
\end{tabular}

Testing would halt approximately once an hour for several minutes while the tethered aerostat was launched to gather weather data up to approximately $500 \mathrm{ft}$. During this time, an array calibration would also be performed with the ground speakers.

Following an ARM flight, the field team would perform additional array calibrations with the sUAS and the ground speakers. The team would then place protective covers on the microphones and store any equipment used during the test day. The SCRAT and the NASA 808 airplane research instrumentation data were typically available the morning after a flight. As a result, the data from one flight was infrequently used to inform future flights. In general, the test team worked through the pre-planned test points and aircraft configurations, and adjusted the test plan for later flights as needed once the acoustic array data had been processed several days later.

\section{B. Flight-Test Plan}

Prior to each ARM flight campaign, the test team would agree on the aircraft configurations and test points to be flown. Each test point would then be prioritized in order to ensure the requisite data were acquired in order to meet the STEAAM and LAGER research objectives. Prioritization of the aircraft configurations and test points allowed for the test team to lay out an executable test plan. Table 6 shows the matrix of the highest priority test points for the SCRAT ARM II flights as an example of the thought that went into preparing for the flights. A standalone flight-test plan document was written for each ARM flight campaign in order to document the objectives for the flight campaign, the planned aircraft configurations, the planned test points, and the planned detailed flight and ground operations. This upfront flight-test planning proved to be invaluable as the team experienced maintenance and weather related delays during the ARM flights. This planning provided an invaluable reference to confirm the team was acquiring the required data. This information also served as a tool to communicate to team members and management the plans for each ARM flight campaign along with the progress. 
Table 6. Example flight-test points for ARM II.

\begin{tabular}{|c|c|c|c|c|c|c|c|c|c|}
\hline Airplane & $\begin{array}{l}\text { LAGER } \\
\text { MLG } \\
\text { fairings } \\
\text { installed }\end{array}$ & $\begin{array}{c}\text { LAGER } \\
\text { cavity } \\
\text { treatment } \\
\text { installed }\end{array}$ & $\begin{array}{l}\text { ACTE } \\
\text { flap } \\
\text { setting }\end{array}$ & $\begin{array}{c}\text { Gear } \\
\text { position }\end{array}$ & KIAS & $\begin{array}{l}\text { Number } \\
\text { of passes }\end{array}$ & Flights & $\begin{array}{c}\text { Total } \\
\text { passes }\end{array}$ & Priority \\
\hline \multirow{6}{*}{ SCRAT } & \multirow{6}{*}{ No } & \multirow{6}{*}{ No } & \multirow{6}{*}{0} & $\mathrm{Up}$ & 140 & 2 & 1 & 2 & 4 \\
\hline & & & & Up & 150 & 3 & 1 & 3 & 2 \\
\hline & & & & Up & 165 & 3 & 1 & 3 & 4 \\
\hline & & & & Down & 140 & 2 & 1 & 2 & 4 \\
\hline & & & & Down & 150 & 3 & 1 & 3 & 2 \\
\hline & & & & Down & 165 & 2 & 1 & 2 & 4 \\
\hline \multirow{6}{*}{ SCRAT } & \multirow{6}{*}{ No } & \multirow{6}{*}{ No } & \multirow{6}{*}{25} & $\mathrm{Up}$ & 140 & 2 & 1 & 2 & 4 \\
\hline & & & & Up & 150 & 3 & 1 & 3 & 1 \\
\hline & & & & $\mathrm{Up}$ & 165 & 2 & 1 & 2 & 4 \\
\hline & & & & Down & 140 & 2 & 1 & 2 & 2 \\
\hline & & & & Down & 150 & 3 & 1 & 3 & 1 \\
\hline & & & & Down & 165 & 2 & 1 & 2 & 2 \\
\hline \multirow{3}{*}{ SCRAT } & \multirow{3}{*}{ No } & \multirow{3}{*}{ Mesh } & \multirow{3}{*}{25} & Down & 140 & 3 & 1 & 3 & 2 \\
\hline & & & & Down & 150 & 3 & 1 & 3 & 1 \\
\hline & & & & Down & 165 & 3 & 1 & 3 & 2 \\
\hline \multirow{3}{*}{ SCRAT } & \multirow{3}{*}{ No } & \multirow{3}{*}{$\begin{array}{c}\text { Chevron } \\
\text { and batting } \\
\text { plate }\end{array}$} & \multirow{3}{*}{25} & Down & 140 & 3 & 1 & 3 & 2 \\
\hline & & & & Down & 150 & 3 & 1 & 3 & 1 \\
\hline & & & & Down & 165 & 3 & 1 & 3 & 2 \\
\hline \multirow{3}{*}{ SCRAT } & \multirow{3}{*}{ Yes } & \multirow{3}{*}{ No } & \multirow{3}{*}{25} & Down & 140 & 3 & 2 & 6 & 2 \\
\hline & & & & Down & 150 & 3 & 2 & 6 & 1 \\
\hline & & & & Down & 165 & 3 & 2 & 6 & 2 \\
\hline \multirow{3}{*}{ SCRAT } & \multirow{3}{*}{ Yes } & \multirow{3}{*}{ Mesh } & \multirow{3}{*}{25} & Down & 140 & 3 & 2 & 6 & 2 \\
\hline & & & & Down & 150 & 3 & 2 & 6 & 1 \\
\hline & & & & Down & 165 & 3 & 2 & 6 & 2 \\
\hline \multirow{3}{*}{ SCRAT } & \multirow{3}{*}{ Yes } & \multirow{3}{*}{$\begin{array}{c}\text { Chevron } \\
\text { and batting } \\
\text { plate }\end{array}$} & \multirow{3}{*}{25} & Down & 140 & 3 & 2 & 6 & 2 \\
\hline & & & & Down & 150 & 3 & 2 & 6 & 1 \\
\hline & & & & Down & 165 & 3 & 2 & 6 & 2 \\
\hline
\end{tabular}

\section{Acoustic Research Measurements Flight Results}

Overall, the ARM flights were accomplished in a safe and successful manner, which allowed for the collection of acoustic and flight data to demonstrate the noise reduction benefits of the STEAAM and LAGER concepts. The data collected showed that the ACTE technology has the potential to reduce airframe noise by approximately $30 \%$ [17]. Table 7 shows the total number of flights, flight hours, and total number of research passes for each of the ARM flight campaigns. For all three phases of the ARM, the actual number of flights flown was less than desired, but determined to be adequate in terms of collecting the minimum required dataset. 
Table 7. Summary of ARM flights, hours, and passes.

\begin{tabular}{|c|c|c|c|}
\cline { 2 - 4 } \multicolumn{1}{c|}{} & \multicolumn{3}{c|}{ Flights } \\
\cline { 2 - 4 } \multicolumn{1}{c|}{} & SCRAT flights & NASA 808 & Total \\
\hline ARM I & 12 & 4 & 16 \\
\hline ARM II & 13 & 4 & 17 \\
\hline ARM III & 15 & 2 & 17 \\
\hline Total & 25 & 8 & 33
\end{tabular}

\begin{tabular}{|c|c|}
\cline { 2 - 2 } \multicolumn{1}{c|}{} & $\begin{array}{c}\text { Total flight } \\
\text { hours }\end{array}$ \\
\hline ARM I & 38.7 \\
\hline ARM II & 42.1 \\
\hline ARM III & 49.7 \\
\hline Total & 80.8
\end{tabular}

\begin{tabular}{|c|c|c|c|}
\hline & \multicolumn{3}{|c|}{ Research passes } \\
\hline & $\begin{array}{c}\text { Number of } \\
\text { passes within } \\
\text { altitude and } \\
\text { offset required }\end{array}$ & $\begin{array}{c}\text { Total } \\
\text { number of } \\
\text { passes }\end{array}$ & $\begin{array}{c}\text { Percentage } \\
\text { of good } \\
\text { passes }\end{array}$ \\
\hline ARM I & 234 & 279 & $84 \%$ \\
\hline ARM II & 277 & 307 & $90 \%$ \\
\hline ARM III & 419 & 465 & $90 \%$ \\
\hline Total & 930 & 1051 & $88 \%$ \\
\hline
\end{tabular}

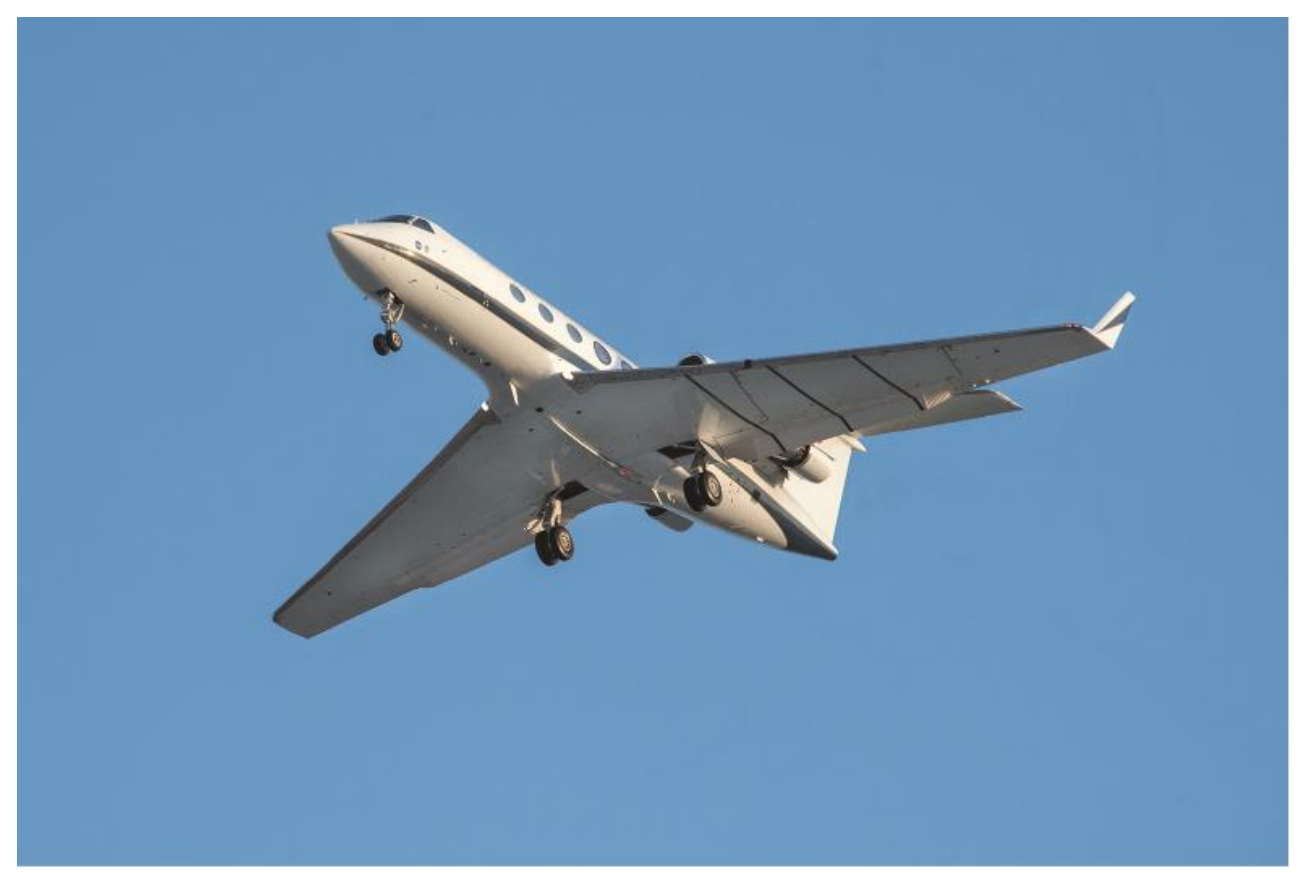

Fig. 17. The SCRAT passing over the microphone array with the MLG fairings, mesh cavity treatment, and ACTE flaps installed.

Both the SCRAT and the NASA 808 airplane are approximately 35 years old and require considerable maintenance. In addition, as a research aircraft, the SCRAT is flown infrequently, which does not allow for many opportunities for the aircrew to identify maintenance issues, or for the ground grew to remedy them. The start of both ARM I and ARM II were delayed several weeks as regularly scheduled maintenance ran longer than planned. ARM II occurred over an eight-week time period in 2017, yet consisted of only one additional flight when compared to ARM I which occurred over a six-week period in 2016. The main reason for the lower average weekly flight rate during ARM II was a number of aircraft maintenance issues with both the SCRAT and the NASA 808 airplane. Several flight days were lost as a result of these maintenance issues. During ARM I and ARM II, having access to both the SCRAT and the NASA 808 airplane was useful in that if one airplane was unavailable for a maintenance reason, then the other aircraft could fill in. Using the NASA 808 airplane allowed for a larger number of flights to be accomplished than if the SCRAT were the sole aircraft. Weather was the other principle factor in the number of lost flight days. 
There were a number of flight days in each of the ARM flight campaigns when the weather was not within the temperature, humidity, and wind limits required for data collection. The test team attempted to minimize the maintenance and weather impacts on data collection primarily by extending the ARM test window as long as possible. Historical weather data were used to estimate the maximum test window with a reasonable probability of containing acceptable weather.

The location of the acoustic array on a lakebed proved to be an issue for ARM II. The test team was denied access to the lakebed following an unusually intense weekend thunderstorm, which left the lakebed near the array site inaccessible. Fortunately, the array site itself was not inundated with water, and permission was granted by the EAFB airfield management office to return to the array site after a delay of just one day. In addition, the location of the array on EAFB for ARM I, II, and III is within airspace that is frequently used by other Air Force projects. Placing the array below restricted airspace required constant coordination with the EAFB airfield and airspace management offices in order to de-conflict with other Air Force projects. This de-confliction resulted in the test team cutting some test days short in order to compromise and share the airspace with other projects. On the whole, the choice of locating the array on the lakebed at EAFB was acceptable, but this choice did require significant effort to de-conflict with other projects and came with a rain related weather risk for ARM I and II. The increased likelihood of rain occurring during the spring timeframe was the reason for relocating the array to another runway for ARM III.

For the ARM flights, the ACTE flaps were flown far more and for longer times at higher flap deflections than they had been originally intended to be flown. The ACTE flaps held up very well overall during the ARM flights, meaning they required no noteworthy repairs, but they did require inspections after every flight and detailed inspections after every fifth flight. A full down day was required when the full inspection had to be performed, resulting in the loss of a potential flight day. In addition, additional time was needed to manually change the ACTE flap position. When the testing required a different ACTE flap position, a potential flight day was lost when the ACTE flaps were repositioned. The test team attempted to minimize these ACTE related delays by adjusting the flight plan to perform the positioning operations and the full inspections on the same day in order to minimize downtime. An attempt was also made to fly the NASA 808 airplane on the days when the SCRAT was down for ACTE inspections or positioning operations.

Maintenance, weather, de-confliction with other projects, and the unique nature of the ACTE flaps presented a number of variables that changed sometimes on an hourly basis. The test team was in constant communication as to the aircraft status and was able to adjust flight plans on very short notice. This flexibility and communication proved key to maximizing the number of ARM flights.

\section{Conclusion}

This paper described flight and ground operations required to support the National Aeronautics and Space Aadministration Acoustics Research Measurements (ARM) project. The ARM flight and ground operations were accomplished in a safe and successful manner, which allowed for the collection of acoustic and flight data to demonstrate the noise reduction benefits of the Adaptive Compliant Trailing Edge (ACTE) flaps, the LAnding Gear noisE Reduction (LAGER) main landing gear fairings, and the LAGER main landing gear cavity treatments. Preliminary analysis of the acoustic data collected showed that the ACTE technology has the potential to reduce airframe noise by approximately $30 \%$. The ARM flights gathered several hundred passes of data for numerous aircraft configurations. This extensive dataset will be used to definitively quantify the acoustic benefits of the ACTE and LAGER technologies.

\section{References}

[1] Khorrami, M. R., Lockard, D. P., Humphreys, W. M. Jr., Choudhari, M. M., and Van De Ven, T., "Preliminary Analysis of Acoustic Measurements from the NASA-Gulfstream Airframe Noise Flight Test,” AIAA-2008-2814, 2008. doi: $10.2514 / 6.2008-2814$

[2] Streett, C. L., Casper, J. H., Lockard, D. P., Khorrami, M. R., Stoker, R. W., Elkoby, R., Wenneman, W. F., and Underbrink, J. R., "Aerodynamic Noise Reduction for High-Lift Devices on a Swept Wing Model," AIAA-2006-212, 2006. doi: 10.2514/6.2006-212

[3] Khorrami, M. R., Humphreys, W. M. Jr., Lockard, D. P., and Ravetta, P. A., “Aeroacoustic Evaluation of Flap and Landing Gear Noise Reduction Concepts," AIAA-2014-2478, 2014. doi: 10.2514/6.2014-2478

[4] Miller, E. J., Lokos, W. A., Cruz, J., Crampton, G., Stephens, C. A., Kota, S., Ervin, G., and Flick, P., “Approach for Structurally Clearing an Adaptive Compliant Trailing Edge Flap For Flight," Society of Flight Test Engineers 46th International Annual Symposium, Lancaster, California, September 14-17, 2015. 
[5] Cumming, S. B., Smith, M. S., Ali, A. N., Bui, T. T., Ellsworth, J. C., and Garcia, C. A., “Aerodynamic Flight-Test Results for the Adaptive Compliant Trailing Edge," AIAA-2016-3855, 2016. doi: 10.2514/6.2016-3855

[6] Herrera, C., Spivey, N. D., and Lung, S-f., “Aeroelastic Response of the Adaptive Compliant Trailing Edge Transition Section," AIAA-2016-0467, 2016. doi: $10.2514 / 6.2016 / 0467$

[7] Humphreys, W. M. Jr., Lockard, D. P., Khorrami, M. R., Culliton, W. G., McSwain, R. G., Ravetta, P. A., and Johns, Z., "Development and Calibration of a Field-Deployable Microphone Phased Array for Propulsion and Airframe Noise Flyover Measurements," AIAA-2016-2898, 2016. doi: $10.2514 / 6.2016-2898$

[8] Humphreys, W. M. Jr., Lockard, D. P., Khorrami, M. R., Culliton, W. G., and McSwain, R. G., "Evaluation of Methods for InSitu Calibration of Field-Deployable Microphone Phased Arrays," AIAA- 2017-4176, 2017. doi: 10.2514/6.2017-4176

[9] AVEC, Time Domain Beamforming Software, Ver. 2.70, AVEC, Inc., Blacksburg, Virginia, URL: http://www.avecengineering.com/products.html [retrieved 29 March 2018].

[10] Baumann, E., Hernandez, J., and Ruhf, J. C., “An Overview of NASA's Subsonic Research Aircraft Testbed (SCRAT)," NASA/TM-2013-216595, 2013.

[11] Kota, S., Flick, P., and Collier, F., "Flight Testing of the FlexFloilTM Adaptive Compliant Trailing Edge," AIAA-2016-0036, 2016. doi: $10.2514 / 6.2016-0036$

[12] Kota, S., Osborn, R., Ervin, G., Maric, D., Flick, P., and Paul, D., "Mission Adaptive Compliant Wing - Design, Fabrication and Flight Test," RTO-MP-AVT-168-18, 2009.

[13] The Goodyear Tire \& Rubber Company, "Global Aviation Tires,” URL: https://www.goodyearaviation.com/resources/pdf/ databook_7_2016.pdf [retrieved 29 March 2018].

[14] Waggoner, E. R., Cliatt, L. J. III, Hill, M. A., and Haering, E. A. Jr., “An Overview of Lessons Learned from Sonic Boom Flight Research Projects Conducted by NASA Armstrong Flight Research Center,” AIAA-2018-\#\#\#\#, (to be published), 2018.

[15] U.S. Department of Transportation Federal Aviation Administration, "Noise Standards: Aircraft Type and Airworthiness Certification," AC No. 36-4C, July 2003.

[16] Lockard, D. P., and Bestul, K. A., "Airframe Noise Flight Tests - NASA FDC Project the Impact of Local Meteorological Conditions on Airframe Noise Flight Test Data," AIAA-2018-\#\#\#, (to be published), 2018.

[17] Beaty, Jelisa, "Hear This: 30 Percent Less Noise," National Aeronautics and Space Administration Armstrong Flight Research Center, URL: https://www.nasa.gov/centers/armstrong/feature/ACTE_30_percent_less_noise.html [retrieved 29 March 2018]. 